\title{
On the Variability of Antarctic Circumpolar Current Fronts Inferred from 1992-2011 Altimetry*
}

\author{
YONG SUN KIM \\ Ocean Science and Technology School, Korea Maritime and Ocean University, Busan, and Ocean Circulation and \\ Climate Research Department, Korea Institute of Ocean Science and Technology, Ansan, South Korea
}

\section{AlejANDRO H. ORSI}

Department of Oceanography, Texas A\&M University, College Station, Texas

(Manuscript received 8 October 2013, in final form 23 September 2014)

\begin{abstract}
Antarctic Circumpolar Current (ACC) fronts, defined as water mass boundaries, have been known to respond to large-scale atmospheric variabilities, especially the Southern Hemisphere annular mode (SAM) and El Niño-Southern Oscillation (ENSO). Distinct patterns of localized variability in meridional front displacements during 1992-2011 are derived from the analysis of satellite sea surface height data. Major basinscale differences are found between the southeast Pacific $\left(150^{\circ}-90^{\circ} \mathrm{W}\right)$ and the southeast Indian $\left(75^{\circ}-150^{\circ} \mathrm{E}\right)$ sectors of the ACC. Frontal positions in the southeast Pacific show large year-to-year meridional fluctuations, attributed mostly to ENSO and in part SAM, and no apparent seasonal cycles or long-term trends. In contrast, summer (winter) frontal locations in the southeast Indian extend farther to the south (north) of their longterm mean distribution. A southward drift of ACC fronts is indicated over the Indian sector during the past two decades. This long-term shift is not directly related to the atmospheric variabilities, but this is most likely in response to changes in large-scale ocean circulation, in particular to the poleward expansion of the Indian subtropical gyre. The existence of these localized, contrasting variability patterns suggests that a circumpolaraveraging analysis could possibly smooth out a local climate signal, with an emphasis on a basin-scale investigation for climate studies in the Southern Ocean.
\end{abstract}

\section{Introduction}

The Antarctic Circumpolar Current (ACC) plays a crucial role in the Southern Ocean, and a knowledge of its structure and variability is essential for understanding global climate changes (Sloyan and Rintoul 2001; Toggweiler and Russell 2008; Morrison and Hogg 2013; Wang et al. 2014). Its path between subtropical and subpolar circulations is delineated by the Subtropical Front (STF) and the southern boundary of the ACC (SBdy); the bulk of its transport is carried out by multiple deep-reaching jets, of which three correspond to

\footnotetext{
* Supplemental information related to this paper is available at the Journals Online website: http://dx.doi.org/10.1175/JPO-D-13-0217.s1.

Corresponding author address: Yong Sun Kim, Korea Institute of Ocean Science and Technology, 787 Haean-ro, Sangrok-gu, Ansan, 426-744, South Korea.

E-mail: yongskim@kiost.ac
}

the circumpolar Subantarctic Front (SAF), the Polar Front (PF), and the southern ACC Front (sACCf) from north to south (see Fig. 1a; Orsi et al. 1995). This robust frontal system acts as a thermohaline boundary between subtropical and subpolar regimes (Naveira Garabato et al. 2011). Therefore, even a minor change in their meridional position could give a nontrivial impact, not only on volume transport (Morrison and Hogg 2013), but also on a hydrological cycle associated with sea ice extent (Liu and Curry 2010).

ACC fronts, defined as water mass boundaries, have been traced around Antarctica by means of specific indicators, that is, particular subsurface water property values from in situ hydrographic data (Nowlin and Clifford 1982; Orsi et al. 1995; Belkin and Gordon 1996). To overcome the spatial and temporal restrictions inherent in these observations, remote sensing data have been used to track sea surface signals associated with the fronts (e.g., Gille 1994; Dong et al. 2006). Sokolov and Rintoul (2002) suggested that a selection of contours in 

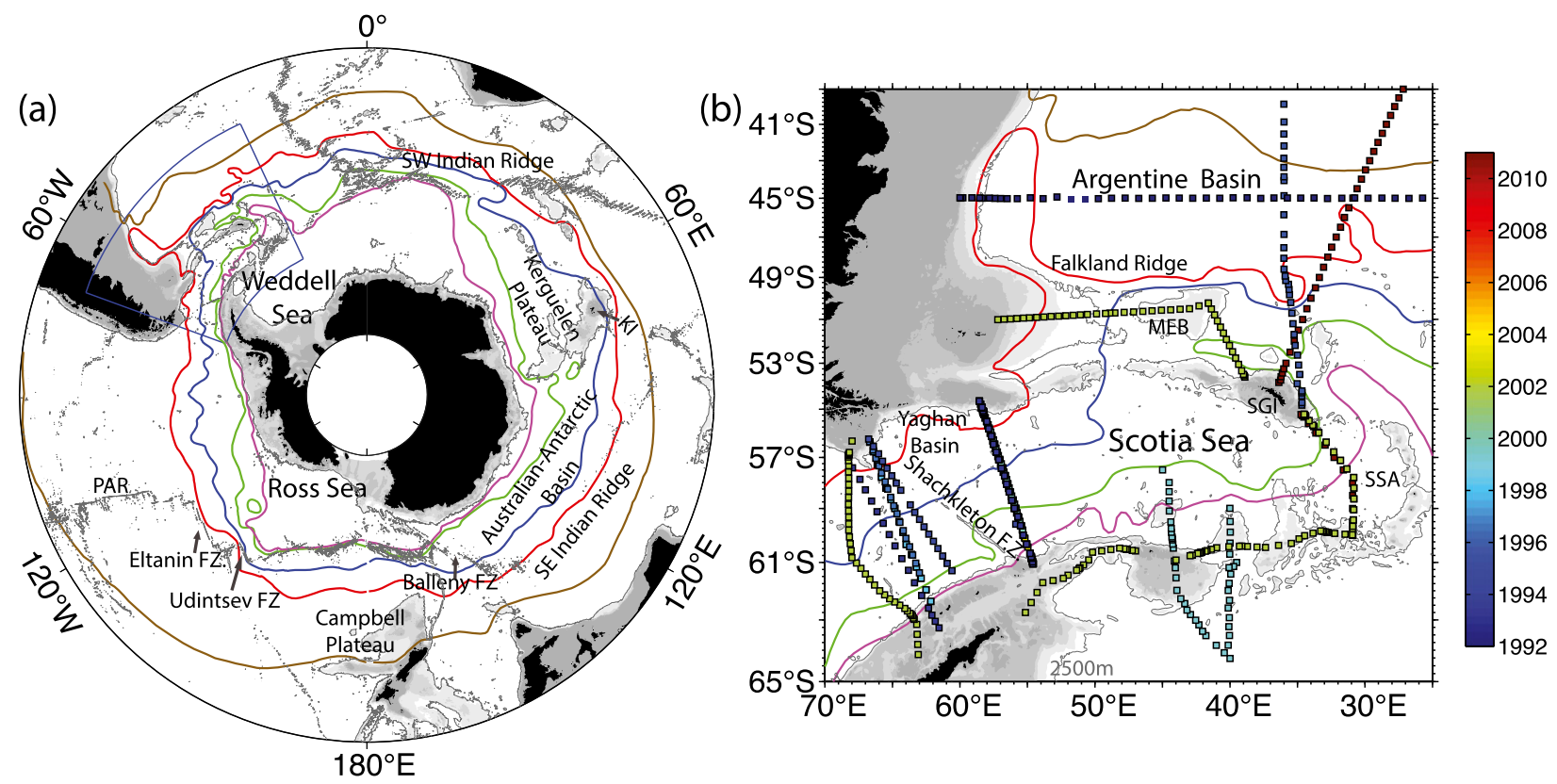

FIG. 1. (a) Bathymetry and frontal distribution in the Southern Ocean; the color lines are locations from Orsi et al. (1995) for the STF (tan), SAF (red), PF (blue), sACCf (green), and SBdy (magenta); the thin gray contour is the 2500-m isobath, and water depths shallower than $2000 \mathrm{~m}(1000 \mathrm{~m})$ are lightly (darker) shaded. (b) The squares show the 610 CTD stations analyzed in this study, color-coded according to observation time, from 16 hydrographic cruises in the southwest Atlantic [the blue box in (a)]; labels are shown for the Kerguelen Islands (KI), the Pacific Antarctic Ridge (PAR), the Maurice Ewing Bank (MEB), South Georgia Island (SGI), and the South Scotia Arc (SSA).

altimetry sea surface height (SSH) could effectively trace frontal locations in a region. Those particular streamlines appeared to be tightly aligned with narrow current jets observed between Tasmania and Antarctica (Sokolov and Rintoul 2007) and also throughout the Southern Ocean with no substantial changes during the altimetry era (Sokolov and Rintoul 2009a,b). Recently, the applicability of this contour-based approach has been a subject of debate, especially on detecting a regional current jet (Graham et al. 2012; Thompson and Sallée 2012; de Boer et al. 2013; Gille 2014). A comparison study between common jet detection methods (Chapman 2014), however, demonstrated that this contour method has advantages for studying dynamic jets linked with hydrographic fronts with superior accuracies at all signal-tonoise ratios (SNRs). Additional satisfactory applications of this methodology have been tested in regions of little topographic control on frontal paths showing large meridional fluctuations at the Greenwich meridian (Billany et al. 2010), south of Africa (Swart et al. 2010), and in the southeast Pacific $\left(105^{\circ} \mathrm{W}\right.$; Sallée et al. 2008).

Changes in the wind system have been regarded as a dominant factor inducing the variability of the ACC fronts (e.g., Böning et al. 2008; Gille 2008; Toggweiler and Russell 2008). It is generally agreed that westerly winds have significantly intensified and contracted toward the Antarctic continent in the past few decades (Marshall 2003; Swart and Fyfe 2012), a climatic signal indicated by a positive trend in the Southern Hemisphere annular mode (SAM). Studies of the ACC responses to the symmetric wind changes have shown, however, rather conflicting results.

Böning et al. (2008) reported the warming and freshening of surface to middepth waters in the ACC based on reconstructed hydrographic data since the 1960s and attributed these changes to a 50-80-km poleward shift of the ACC. Sallée et al. (2008) argued that ACC migrations are zonally asymmetric responses to a uniform change in the westerlies as fronts travel over regions with very different regimes of Ekman transport anomalies. Northward (southward) frontal shifts are expected within divergences (convergences), for example, in the Pacific (AtlanticIndian) sector during positive SAM periods, whereas no detectable change in frontal locations was observed in the transitional sector (Indo-Pacific). Results from an eddyresolving coupled climate model (Graham et al. 2012; de Boer et al. 2013) showed no noticeable displacements of ACC fronts when forced with quadrupled $\mathrm{CO}_{2}$ concentrations during 100 model years, arguing that the relatively weak stratification of the ACC allows the fronts to be tightly constrained by local bottom topographies. Historical simulations by the Coupled Model Intercomparison Project phase 5 (CMIP5) also reported no significant relationship between the latitudinal positions of the ACC fronts and the westerlies (Meijers et al. 2012). 
The teleconnection of El Niño-Southern Oscillation (ENSO; Turner 2004) makes understanding the observed variability of the ACC fronts even more challenging. Sallée et al. (2008) postulated that meridional positioning of the ACC was linked more highly with ENSO than SAM on time scales greater than a year and particularly in the ENSO-dominated Pacific-Atlantic sector (Yuan 2004; Lee et al. 2010).

In this paper, we aim to provide a comprehensive view on understanding the intricate variability of the ACC fronts based on 19 years of satellite altimetry data. Details on the datasets and methods used in this study are provided in sections 2 and 3. Section 4 describes the inferred spatial distribution and temporal variability of the fronts and their selective response to atmospheric variabilities. A revised mechanism controlling the regional variability of the fronts is introduced in section 5 . The conclusions are given in section 6 .

\section{Data}

\section{a. Satellite altimetry data}

For this study, the absolute SSH was calculated by adding a mean dynamic topography (MDT) to sea level anomaly (SLA) fields obtained from the Centre $\mathrm{Na}$ tional d'Etudes Spatiales (CNES)/Collecte Localisation Satellites (CLS) Archiving, Validation, and Interpretation of Satellite Oceanographic data (AVISO; www. aviso.oceanobs.com; Ducet and Le Traon 2001; AVISO 2009). A total of 954 weekly time series of SSH were analyzed between 14 October 1992 and 19 January 2011 on a Mercator grid with a horizontal resolution of $1 / 3^{\circ}$ at the equator. The meridional resolution is gradually decreased with latitude, becoming around $1 / 6^{\circ}(18.5 \mathrm{~km})$ at $60^{\circ} \mathrm{S}$. We took advantage of the recently released MDT_CNES_CLS09 (Rio et al. 2009), an updated version of the widely used MDT derived by Rio and Hernandez (2004). Noticeable improvements are that Rio et al. (2009) used the 2.5-yr extended Gravity Recovery and Climate Experiment (GRACE) data for a first-guess field and included Argo profiles for their dynamic height computations. During processing, they adopted an improved Ekman model and optimal filter instead of a 400-km Gaussian filter, which allows 2 times higher grid resolution $\left(1 / 4^{\circ}\right)$.

A root-mean-square (RMS) error in $\mathrm{SSH}$ is 1.84 dyn $\mathrm{cm}$ averaged over the southwest Atlantic (the blue box in Figs. 1a,b), but this error increases up to $5 \mathrm{dyn} \mathrm{cm}$ along the Antarctic Peninsula, probably because of the insufficient data points near the coasts, indicating the potential for a limitation to using altimetry to track the SBdy around Antarctica. Overall the RMS error across the ACC is, however, less than 1 dyn $\mathrm{cm}$.

\section{b. CTD profiles}

Our first goal is to find a set of particular SSH contours (or streamlines) that are tightly associated with hydrographic fronts identified by a traditional approach based on water property criteria (Orsi et al. 1995). Thus, we examined all the available high-quality hydrographic data during the span of the SSH time series within the southwest Atlantic (Fig. 1b). This dataset consisted of 16 cruises with 614 CTD profiles taken from the United States, Chile, and the United Kingdom (extracted from http://woceatlas. tamu.edu). These CTD stations provided good spatial coverage, as shown in Fig. 1b. Although most cruises were occupied during the austral summer, more than one-third of the total CTD stations from Deep Ocean Ventilation through Antarctic Intermediate Layers (DOVETAIL), Antarctic Large Scale Box Analysis and the Role of the Scotia Sea (ALBATROSS), and A23 were occupied during the fall and winter seasons, giving us confidence that a surmised relationship between the SSH and hydrographic fronts does not seem to have a seasonal bias.

\section{c. Argo floats}

To study the spatial correspondence between satellite altimetry, dynamic height, and current field at parking level, a total of 207407 Argo profiles obtained during February 2002-August 2011 were investigated. These profiles covered most of the ACC region without any seasonal bias, thus providing unique in situ observational information in space and time. Here, we only used qualified profiles deeper than $400 \mathrm{~m}$ that passed the Argo real-time quality control (e.g., flagged as "good" only data). Any outliers and spikes in a profile were flagged by checking the overall data ranges $\left(T \geq 35^{\circ} \mathrm{C}\right.$ and $T \leq-2^{\circ} \mathrm{C}, S \geq 37$ and $S \leq 10$, and $P \geq 2100 \mathrm{dbar}$ ), standard deviations $(\geq 3.5 \sigma)$, and neutral density instabilities $\left(\Delta N<-0.01 \mathrm{~kg} \mathrm{~m}^{-3}\right)$.

An individual trajectory provides instantaneous current information at parking level with relatively high accuracy. Any error in the current estimation from trajectories is generally less than $0.5 \mathrm{~cm} \mathrm{~s}^{-1}$ (Park et al. 2005), which is one or two orders smaller than the ACC currents. To generate a climatological current field, the estimated currents were objectively mapped onto a $1 / 4^{\circ}$ grid with a $1.25^{\circ}$ correlation length scale at a parking level of 1000 dbar.

\section{d. The SAM and ENSO indices}

We used two climate indices representing dominant atmospheric variabilities in the Southern Ocean: the SAM index (Marshall 2003; downloaded from www. nerc-bas.ac.uk/icd/gjma/sam.html) and the bivariate ENSO index (Smith and Sardeshmukh 2000; from www. cdc.noaa.gov/people/cathy.smith/best). 
Marshall (2003) provided the SAM index, calculated as a difference in the normalized mean sea level pressure (SLP) from six station pairs at $40^{\circ}$ and $65^{\circ} \mathrm{S}$ bands, thus indicating the relative strength of the meridional atmospheric pressure gradient between mid- and high latitudes. In the case of ENSO, Smith and Sardeshmukh (2000) suggested a bivariate ENSO index by averaging a standardized Niño-3.4 SST time series and a standardized Southern Oscillation index (SOI) to represent the ocean-air coupled characteristics of ENSO. The correlation coefficient between the bivariate ENSO and traditional ENSO index, Niño-3.4, was 0.90 for the study period. We assumed that values greater than one standard deviation $(\mathrm{ENSO}>1)$ indicated $\mathrm{El}$ Niño and vice versa for La Niña (ENSO $<-1$ ).

\section{e. Other satellite datasets}

To investigate climate changes accompanied by ACC frontal variability, we used a monthly averaged time series of sea ice concentration from passive microwave satellites (Comiso 2012) and an Advanced Very High Resolution Radiometer (AVHRR)-based, objectively interpolated sea surface temperature (OISST.v4; Reynolds et al. 2007) for the last three decades (19812011). These datasets have a spatial resolution of about $1 / 4^{\circ}(\sim 25 \mathrm{~km})$.

\section{Altimetry frontal indicators}

\section{a. Methodology}

Following the hypothesis that regionally obtained altimetry frontal indicators hold for the entire ACC (Sokolov and Rintoul 2009a), we selected the southwest Atlantic as a test area, which includes Drake Passage, the Scotia Sea, and the Argentine basin (see Fig. 1b). Traditional front definitions were first developed based on the knowledge from Drake Passage (Nowlin and Clifford 1982), mainly due to its ship accessibility, which gives the advantage of large numbers of historical hydrographic observations. In particular, the Passage squeezes the hydrographic structure of the ACC down this narrow choke point, causing fronts to be closely spaced, resulting in a condensed, complicated ACC frontal structure with enhanced mesoscale eddy activity (Chereskin et al. 2009). The Scotia Sea is unique in the Southern Ocean because of its large-scale topographic features. Meridionally aligned ridges act as obstacles and steer the ACC northward to compensate for its loss of potential vorticity. One noteworthy feature of this test area is the Malvinas-Brazil confluence, which allows us to evaluate the applicability of altimetry indicators on such confluence regions.
To retrieve SSH contours (or streamlines) associated with the fronts in this test area, we checked three independent approaches by checking the sea level slope $(\Delta \mathrm{SSH})$, the SSH frequency, and the traditional water property criteria. With the well-known assumption that a specific streamline is persistently aligned with a current core (e.g., Sokolov and Rintoul 2007, 2009a), the streamline corresponding to a front should appear with its maximum slope concurrently with its minimum frequency (Thompson and Sallée 2012). Moreover, the streamline should also agree with a traditional, hydrographic front inferred from the water property criteria. Thus, as a starting point, we investigated the relationship between an averaged $\Delta \mathrm{SSH}$ (the black line in Fig. 2a) and the corresponding SSH values by using all the spatiotemporal data (11582178) within the southwest Atlantic. This approach rendered four distinct peaks in $\Delta \mathrm{SSH}$ at $-3.5,-38,-61$, and $-98.5 \mathrm{dyn} \mathrm{cm}$, corresponding to the well-documented current cores in this region (Lenn et al. 2007; Chereskin et al. 2009; Renault et al. 2011). As expected, these streamlines appeared precisely at their minimum frequencies (the gray line in Fig. 2a), confirming that these peaks are certainly associated with strong current cores (Thompson and Sallée 2012).

Furthermore, we compared these streamlines with the classical criteria for ACC fronts. Following Orsi et al. (1995), high-quality hydrographic profiles in the southwest Atlantic were assigned to particular zones: the Subantarctic (SAZ), the Polar Front (PFZ), the Antarctic (AZ), the boundary (BZ), and the subpolar (SPZ) zones, divided by the ACC fronts and SBdy from north to south. The canonical location of an SAF is generally tracked by the equatorward diving of salinity minimum waters from the surface in the PFZ to an intermediate depth in the SAZ, feeding the salinity minimum layer of the Antarctic Intermediate Water (AAIW). Thus, a steep plunge of surface properties to depths greater than $400 \mathrm{~m}$ is a robust indicator for the SAF. A PF is frequently identified by the northern extension of a subsurface minimum temperature tongue originating from the SPZ. Thus, the northern limit of $2^{\circ} \mathrm{C}$ of this tongue was used as an indicator for the PF. The Upper Circumpolar Deep Water (UCDW) that rises to nearly $200 \mathrm{~m}$ is a key indicator for a sACCf, which was depicted by the southernmost extension of a $2.0^{\circ} \mathrm{C}$ isotherm at the subsurface temperature maximum layer. The transitional band, where the shoaling UCDW enters the colder and well-mixed subpolar region, was used to determine the location of the SBdy.

For comparison, an altimetry value was assigned to each hydrographic profile by applying a cubic spline interpolation for the spatial domain and a linear 


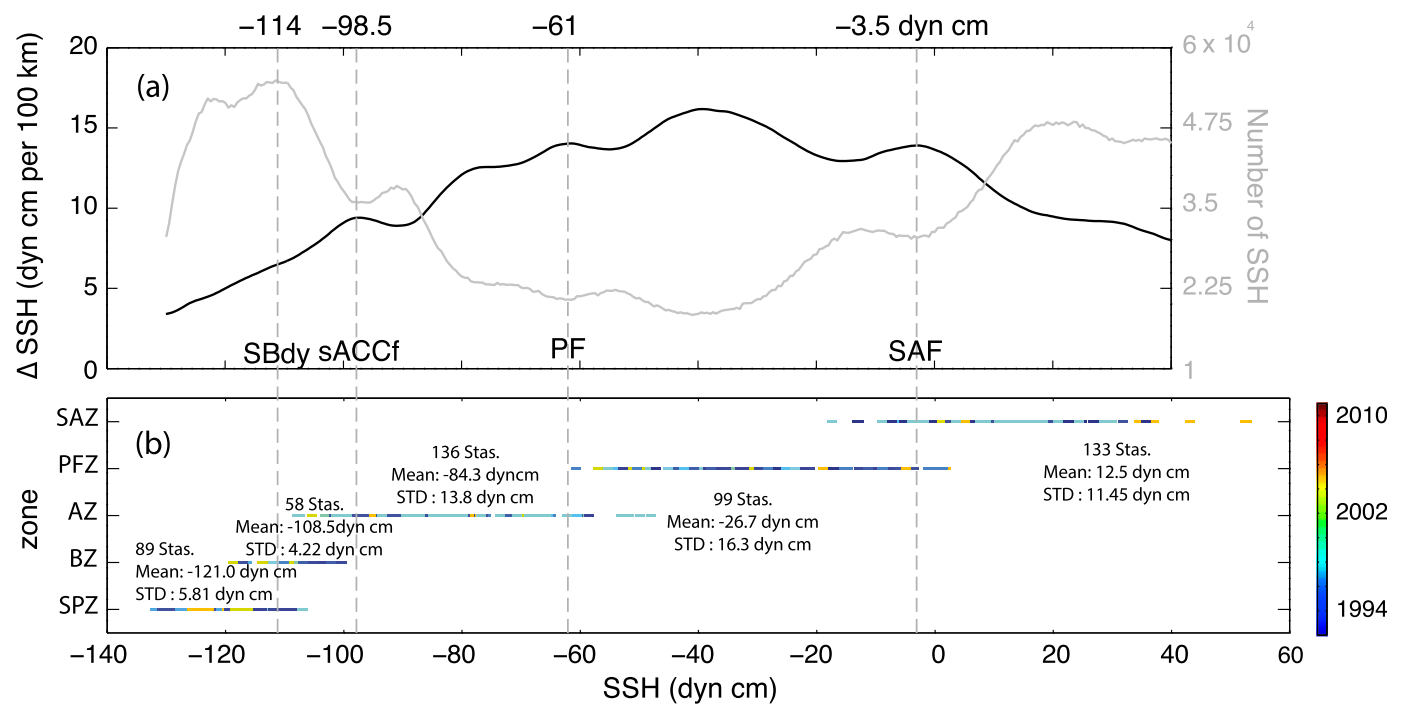

FIG. 2. (a) Meridional SSH gradient (black line) and the census of SSH grid points (gray line); (b) observed zonation based on CTD profiles analyzed in the southwest Atlantic. The three distinct peaks at $-3.5,-61$, and -98.5 dyn $\mathrm{cm}$ are associated with the ACC fronts (SAF, PF, and sACCf), both as maxima (minima) on the SSH gradient (number of SSH), whereas -114 dyn cm was selected to represent the SBdy.

interpolation for the time domain. Figure $2 b$, collectively, shows a strong agreement between the traditional water mass-based classification ( $y$ axis) and the altimetry frontal indicators ( $x$ axis); almost all the CTD profiles in the SAZ (92.6\%), PFZ (90.9\%), and AZ (80.1\%) assigned using the traditional method were resolved with the selected altimetry values of $-3.5,-61$, and $-98.5 \mathrm{dyn} \mathrm{cm}$. A relatively low percentage for the AZ might be a net result of frequently observed cold and warm rings originating from the sACCf and PF flowing over the Shackleton Fracture Zone (Chereskin et al. 2009; Barré et al. 2011). Since the SBdy is essentially density compensating and not associated with a current jet (Orsi et al. 1995), altimetry-based methods failed to render a streamline associated with the SBdy. For the sake of completeness only, the $-114 \mathrm{dyn} \mathrm{cm}$ was selected based on the fact that it maximized the percentage of the CTD profiles assigned to the BZ (91.5\%) and the SPZ (86.6\%). It should also be noted that a single streamline does not need to correspond exactly with a hydrographic front. For instance, the -38 dyn cm streamline, the highest peak in $\triangle \mathrm{SSH}$ (Fig. 2b), is not likely associated with either the PF or the SAF inferred from the traditional method, but is a quasi-persistent and regional current core between these fronts (Fig. $2 \mathrm{~b}$ and Fig. S1 in the supplementary material). This core has been depicted in repeated ADCP observations (Lenn et al. 2007) and is often regarded as the northern branch of the PF generated by interactions between the SAF and $\mathrm{PF}$ at the entrance and exit of the Yaghan basin (Lenn et al. 2007; Cunningham and Pavic 2007), as well as along the northern flank of the Falkland Ridge (Peterson and Whitworth 1989; Orsi et al. 1995), where these two fronts tend to merge and form a robust current jet.

\section{b. The applicability of altimetry indicators}

The applicability of regionally inferred streamlines was theoretically implied by Watts et al. (2001) and Swart et al. (2010); a water particle following a particular streamline would have undergone a similar physical process unless the particle was mixed with waters with different characteristics. This theory implies that ACC fronts could retain their own streamlines around the entire ACC belt.

Support for this theory derives from the time-mean sections of the $\Delta$ SSH in the first (1993) and final (2010) years along $105^{\circ} \mathrm{E}$ (Fig. 3a), and for summer and winter months along $90^{\circ} \mathrm{E}$ (Fig. 3b) within the Indian Ocean, having robust long-term and seasonal displacements in latitudinal positions of the ACC (see section $4 \mathrm{~b}$ for details). Similarly, we also tested changes in the mean $\Delta \mathrm{SSH}$ for El Niño and La Niña periods along $117^{\circ} \mathrm{W}$ within the Pacific (Fig. 3c), where fronts appeared to respond sensitively to atmospheric variabilities (see section 4c). As previous studies have pointed out (Sokolov and Rintoul 2007, 2009a; Graham et al. 2012; Chapman 2014), these examples illustrate that the ACC is composed of multiple filaments, and both the strength (or SSH gradient) and meridional positions of these filaments vary substantially in space and time, reflecting the intricacy of the ACC frontal system on a flat bottom topography (Thompson et al. 2010). It is remarkable 


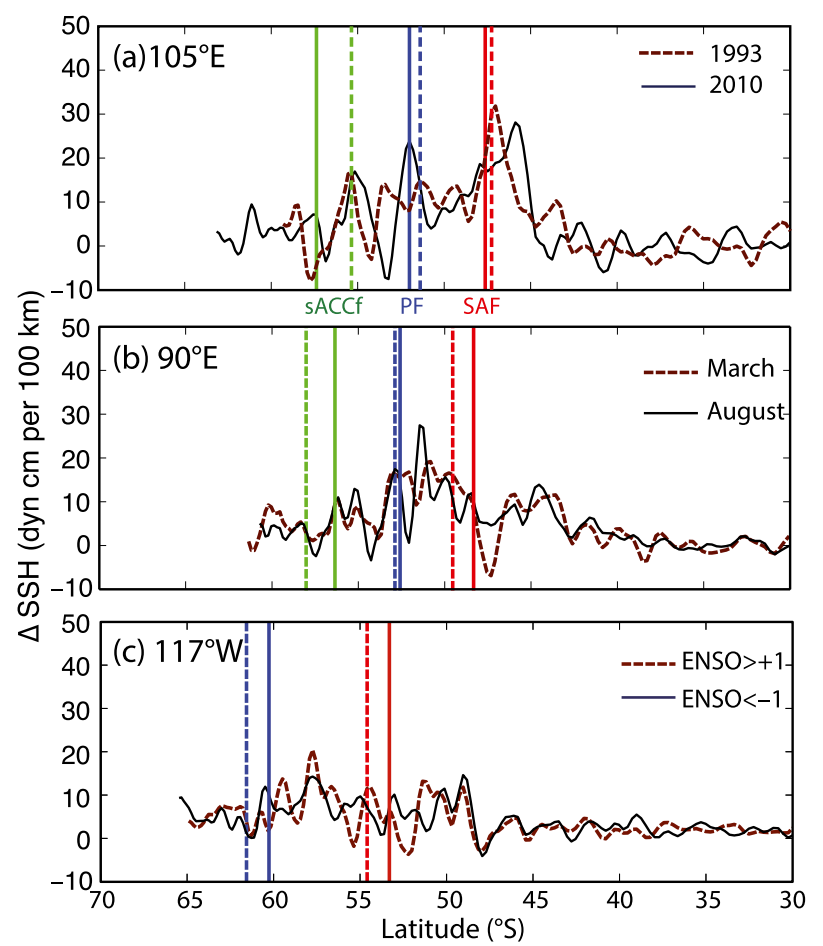

FIG. 3. Mean meridional sea surface height gradient along (a) $105^{\circ} \mathrm{E}$ in 1993 and 2010, (b) $90^{\circ} \mathrm{E}$ in March and August, and (c) $117^{\circ} \mathrm{W}$ during El Niño (ENSO $>+1$ ) and La Niña (ENSO $<-1$ ) periods. The vertical lines correspond to the latitudes for the SAF (red, -3.5 dyn $\mathrm{cm}$ ), PF (blue, -61 dyn $\mathrm{cm}$ ), and sACCf (green, -98.5 dyn $\mathrm{cm})$, respectively.

however, that the selected streamlines generally tracked the enhanced $\Delta \mathrm{SSH}$ on seasonal to long-term time scales even in the Indian and Pacific sectors. For instances, the two southernmost fronts at a longitude of $105^{\circ} \mathrm{E}$ appeared exactly on the peaks of the $\Delta \mathrm{SSH}$ sections and all the fronts at $90^{\circ} \mathrm{E}$ were aligned with strong $\Delta$ SSHs. It is worth mentioning that there were some exceptions: the SAFs slightly missed peaks of the $\Delta \mathrm{SSH}$ sections at $105^{\circ} \mathrm{E}$ during both years, and a similar situation was found for the PF at $117^{\circ} \mathrm{W}$ for the ENSO < -1 periods. These exceptions, as noted by Thompson and Sallée (2012), were probably because of degrading in the $\Delta$ SSH resolutions when taking spatial derivatives of the SSH.

From the altimetry frontal indicators, it can be inferred that there is a long-term poleward shift in the ACC fronts at $105^{\circ} \mathrm{E}$ with a maximum shift of $2^{\circ}$ for the sACCf (Fig. 3a). A direct verification of this substantial shift was limited by the lack of repeated in situ observations; however, the long-term satellite observations of localized, persistent sea surface warming and sea ice retreating within this sector, as we will discuss in section $5 \mathrm{~b}$, are consistent with this frontal shift and seem to suggest indirectly that the fronts have actually experienced a long-term poleward drift. Taken all together, those examples show the stability of the altimetry indicators around the circumpolar belt, which is consistent with the theory as well as with recent studies (Sallée et al. 2008; Sokolov and Rintoul 2009b; Swart et al. 2010; Billany et al. 2010; Langlais et al. 2011; Chapman 2014).

\section{c. Dynamic height}

Figure 4 illustrates that there is an obvious linear relationship between satellite altimetry and the corresponding dynamic heights $(\phi)$ estimated from the CTD profiles within the southwest Atlantic; a high correlation $(r \geq 0.97)$ for a SSH less than 10 dyn $\mathrm{cm}$ hints that a set of dynamic height contours may be applicable as an alternative frontal indicator. Based on this relationship, we compared the SSH indicators with the various dynamic heights used in previous studies as shown in Table 1. The suggested value of $\phi_{1000 \mathrm{dbar}}^{50 \mathrm{dbar}}$ for the sACCf exactly matches that of Thorpe et al. (2002), and the SAF and SBdy lie comfortably within the ACC range suggested by Orsi et al. (1995). The value of $\phi_{1500 \mathrm{dbar}}^{500 \mathrm{dbar}}$ for the SAF is exactly the same as Naveira Garabato et al. (2009), but 0.54 dyn $m$ for the PF (Naveira Garabato et al. 2009) is slightly different from this study $(0.5 \mathrm{dyn} \mathrm{m})$; the climatological-mean position of $0.54 \mathrm{dyn} \mathrm{m}$ is $57.7^{\circ} \mathrm{S}$ at Drake Passage, likely associated with the northern branch of the PF (Lenn et al. 2007), while the 0.5 dyn $\mathrm{m}$ measured in this study is $58.9^{\circ} \mathrm{S}$, consistent with the traditional PF location observed from XBT observations (Sprintall 2003) and shipboard ADCP data (Lenn et al. 2007) at Drake Passage. Interestingly, there is a substantial discrepancy between this study and that of Böning et al. (2008), whose climatological frontal positions were located farther north than this study and the other studies (see the following section for details).

It is worth pointing out that there is a bifurcation in dynamic heights for SSHs higher than 10 dyn cm (Fig. 4), probably representing a confluence of two different source waters, that is, subtropical waters along the Brazil Current and the subantarctic waters of the ACC. This bifurcation makes it difficult to distinguish a single streamline representing the STF, implying that a front, within a confluence region, seems to be hard to pin down to a single streamline because signals from other source waters interrupt the inherent streamlines for ACC waters.

There are remarkable agreements between the synoptic positions of SSH contours associated with ACC fronts and spatial distributions of the dynamic height field (Fig. 5a) as well as the climatological current field (Fig. 5b), providing robust evidence for its applicability to the entire circumpolar belt. The exceptions are narrow abyssal channels, where the SSH contours might 


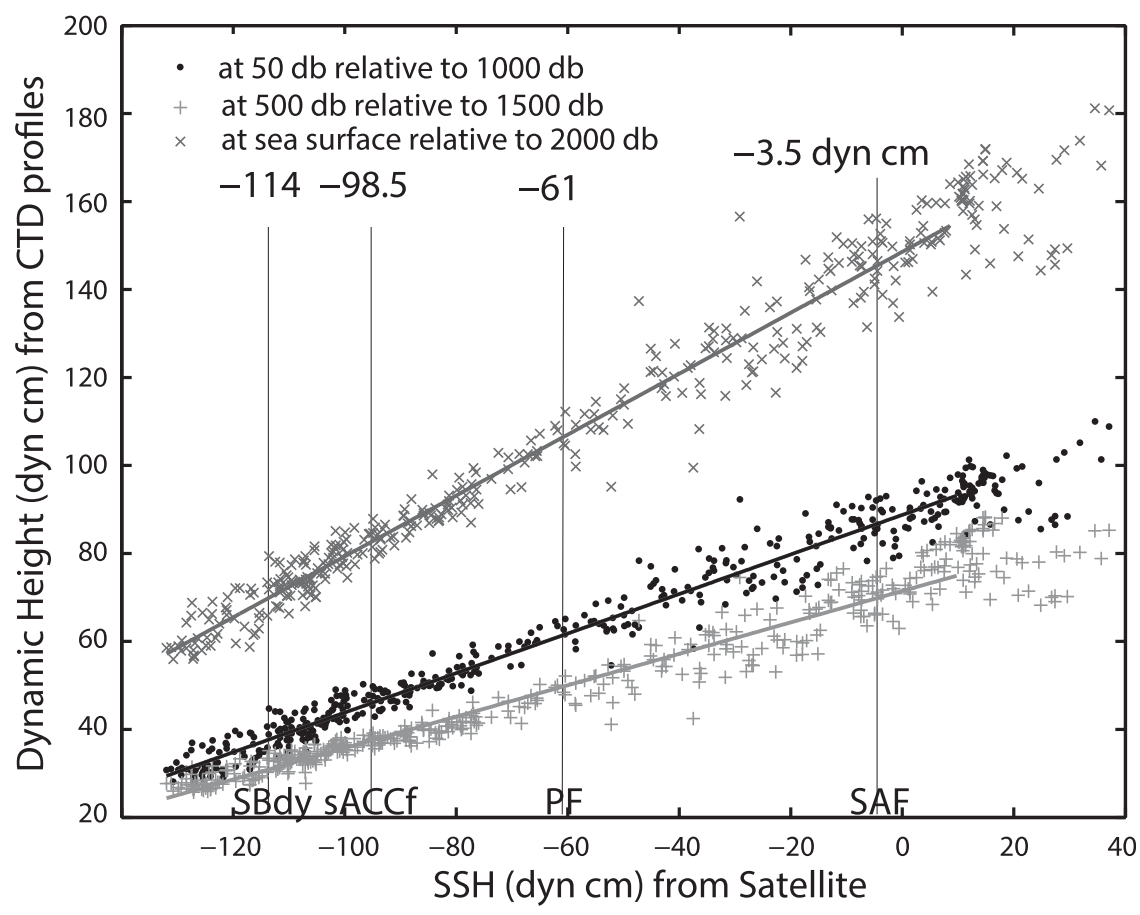

FIG. 4. Sea surface height derived from satellite altimetry vs dynamic height estimated from CTD profiles in the southwest Atlantic (see Fig. 1b); the thick straight lines represent the firstorder least squares fitting; the adopted ACC fronts and SBdy indicators in this study are also shown within the thin vertical lines.

break down in terms of tracking fronts inferred from dynamic height and current fields. One of the most noticeable examples is the SBdy flowing northward along the eastern flank of the Kerguelen Plateau near $80^{\circ} \mathrm{E}$; the climatological speed estimated from the Argo trajectories reaches up to $15 \mathrm{~cm} \mathrm{~s}^{-1}$ at 1000 dbar (Fig. 5b). This strong northwestward extension of continental margin waters, detected from ship-based synoptic observations (Orsi et al. 1999; Park et al. 2009) and current meter moorings (Fukamachi et al. 2010), is well-known as the deep western boundary current (DWBC) of the cyclonic subpolar gyre in the Australian-Antarctic basin. Other abyssal channels might be along the Balleny
Fracture Zone near $150^{\circ} \mathrm{E}$ (Rodman and Gordon 1982) and the South Scotia Arc near $30^{\circ} \mathrm{W}$ (Orsi et al. 1999), where major topographic barriers steer newly ventilated bottom waters away from their sources along the DWBC. These examples are also in accordance with our finding that there is a restriction in the application of SSH streamlines within these confluence regions.

\section{d. Comparison with previous studies}

Mean frontal paths have appeared in previous literature (Orsi et al. 1995; Sallée et al. 2008; Böning et al. 2008; Sokolov and Rintoul 2009a), which can be another validator of newly suggested frontal indicators. Using

TABLE 1. Summary of ACC frontal indicators based on streamlines from satellite altimetry, dynamic height, and previous studies.

\begin{tabular}{lcccc}
\hline \hline Front & SSH $($ dyn cm $)$ & $\phi_{1000 \mathrm{dbar}}^{50 \mathrm{dbar}}($ dyn m $)$ & $\phi_{1500 \mathrm{dbar}}^{500 \mathrm{dbar}}($ dyn m $)$ & $\phi_{2000 \mathrm{dbar}}^{\text {ddbar }}($ dyn m $)$ \\
\hline SAF & -3.5 & $0.87\left(0.9^{\mathrm{a}}\right)$ & $0.70\left(0.7^{\mathrm{b}}\right)$ & $1.46\left(1.73^{\mathrm{c}}\right)$ \\
PF & -61 & 0.62 & $0.50\left(0.54^{\mathrm{b}}\right)$ & $1.06\left(1.43^{\mathrm{c}}\right)$ \\
sACCf & -98.5 & $0.45\left(0.45^{\mathrm{d}}\right)$ & 0.36 & 0.81 \\
SBdy & -114 & $0.38\left(0.35^{\mathrm{a}}\right)$ & 0.31 & 0.70 \\
\hline
\end{tabular}

${ }^{\text {a }}$ Orsi et al. (1995) to represent limits of the ACC.

${ }^{\mathrm{b}}$ Naveira Garabato et al. (2009) to identify the SAF and PF at Drake Passage.

${ }^{\mathrm{c}}$ Böning et al. (2008) to represent the climatological location of the ACC fronts using CSIRO Atlas of Regional Seas gridded atlas in the Southern Ocean. The unit is converted from $\mathrm{m}$ to dyn $\mathrm{m}$ for comparison purpose by dividing by the gravitational coefficient.

d Thorpe et al. (2002) to identify the climatological location of the sACCf near the South Georgia Island. 
(a) Dynamic height (dyn cm) at $50 \mathrm{dbar}$ relative to $1000 \mathrm{dbar}$

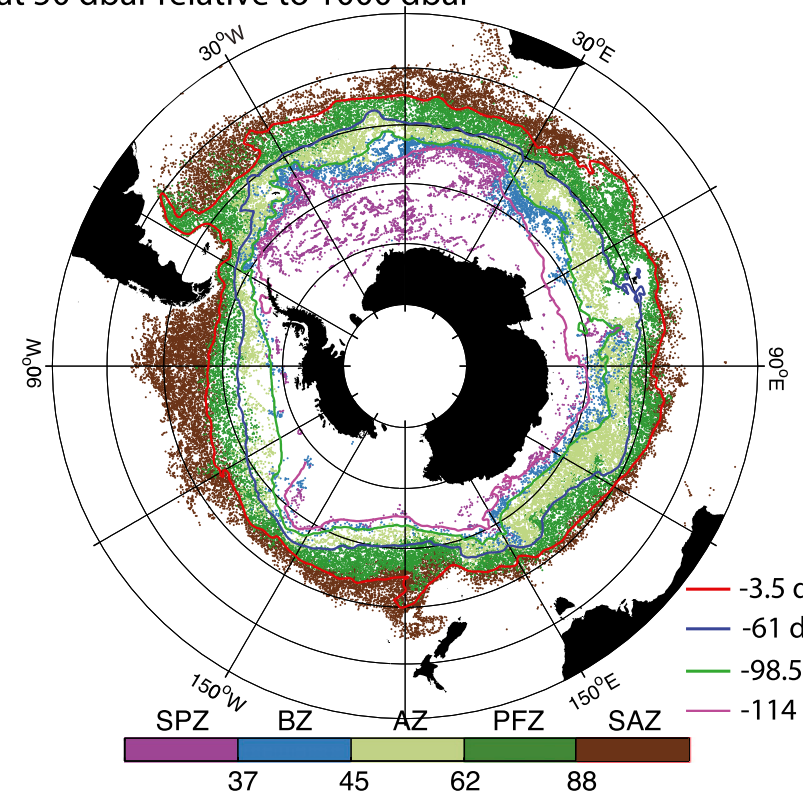

(b) Velocity $(\mathrm{cm} / \mathrm{s})$ at $1000 \mathrm{dbar}$

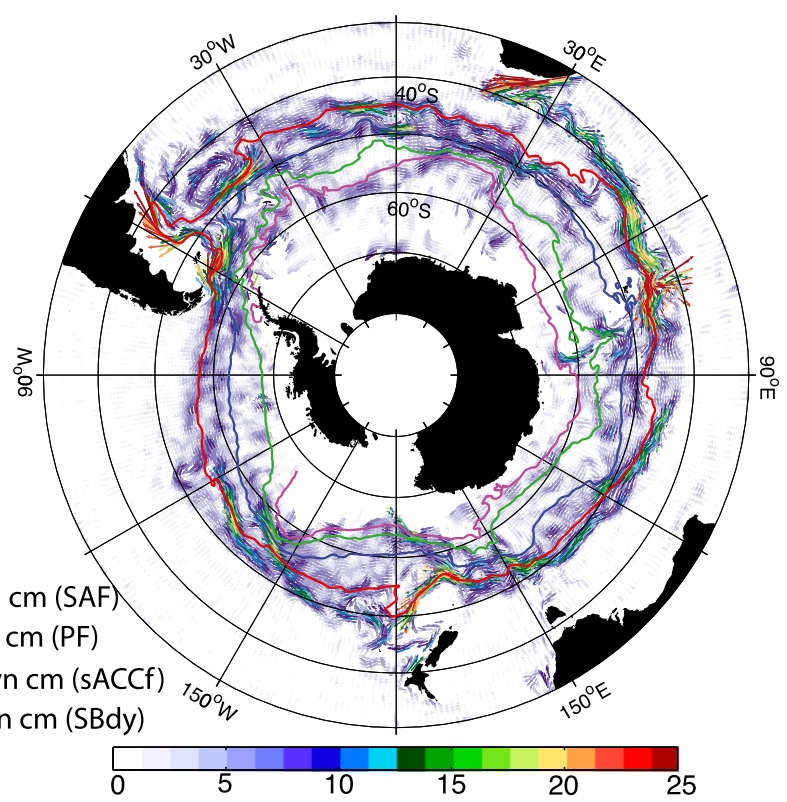

FIG. 5. Argo-derived (a) dynamic height at 50 dbar with respect to $1000 \mathrm{dbar}$, and (b) objectively interpolated velocity field at $1000 \mathrm{dbar}$. The superimposed color contours indicate the mean (1992-2011) distribution of ACC fronts and SBdy using the altimetry indicators derived from this study.

synoptic in situ cruise sections, Orsi et al. (1995) tracked fronts based on specific values of water properties representing distinct water mass changes across those fronts. Sokolov and Rintoul (2009a) used a 15-yr time series of the SLAs with a MDT relative to 2500 dbar that was calculated from the World Ocean Climate Experiment (WOCE) hydrographic climatology. Among filaments for ACC fronts, the middle branch of the SAF and northern branches of the PF and sACCf are used to represent the traditional locations of the fronts. Sallee et al. (2008) extended a series of studies by Sokolov and Rintoul $(2002,2007)$ based on a MDT field generated by combining the Argo and the Southern Ocean Data Base (SODB) dataset. To describe two energetic fronts, they selected 1.20 - and $0.95-\mathrm{m}$ contours relative to $1500 \mathrm{dbar}$ for the SAF and PF, respectively. Böning et al. (2008) mapped the climatological paths of the SAF and PF in the vicinity of 1.7 - and 1.4-m streamlines $\left(\phi_{2000 \mathrm{dbar}}^{0 \mathrm{dbar}}\right)$ using the Commonwealth Scientific and Industrial Research Organisation (CSIRO) Atlas of Regional Seas (CARS) climatology. As mentioned above, the fronts from Böning et al. (2008) showed a substantial northward bias compared to other studies, as illustrated in Fig. 6. The circumpolar mean displacements from this study were $1.35^{\circ}$ for the SAF and $3.0^{\circ}$ for the PF to the north, and these reached up to $7^{\circ}(\mathrm{SAF})$ and $17^{\circ}(\mathrm{PF})$ along the Argentina coast.
Although the front locations from all the other studies are broadly consistent with this study, especially in the vicinity of major topographic features, there are also significant discrepancies in the frontal paths between this study and the previous studies in several locations (Fig. 6). South of the Campbell Plateau at $180^{\circ} \mathrm{E}$, for example, the SAF from this study goes northeastward along the steep continental slope around the southeast flank and then turns back from about $50^{\circ} \mathrm{S}$ before continuing eastward toward the Eltanin Fracture Zone, but the other studies put the path farther south at around $57^{\circ} \mathrm{S}$ (Orsi et al. 1995; Sallée et al. 2008; Sokolov and Rintoul 2009a). Such a topographically constrained SAF in this study is compatible with the hydrographic observations obtained from the United States Naval Ship (USNS) Eltanin cruise 50 along $170^{\circ} \mathrm{E}$ (Gordon 1975). Gordon (1975) measured the northward extent of a salinity minimum layer (i.e., the traditional definition of the SAF) starting just south of the Campbell Plateau escarpment. Independent studies, in order to track the $\mathrm{SAF}$, using a $8^{\circ}-8.5^{\circ} \mathrm{C}$ indicator (Uddstrom and Oien 1999) and following a deep current jet based on numerical simulations (Tilburg et al. 2002; Langlais et al. 2011; Graham et al. 2012; Graham and de Boer 2013; Chapman 2014), showed the same northward turn of the SAF steered by bottom topography as in this study. The difference in the position of the SAF between this study 

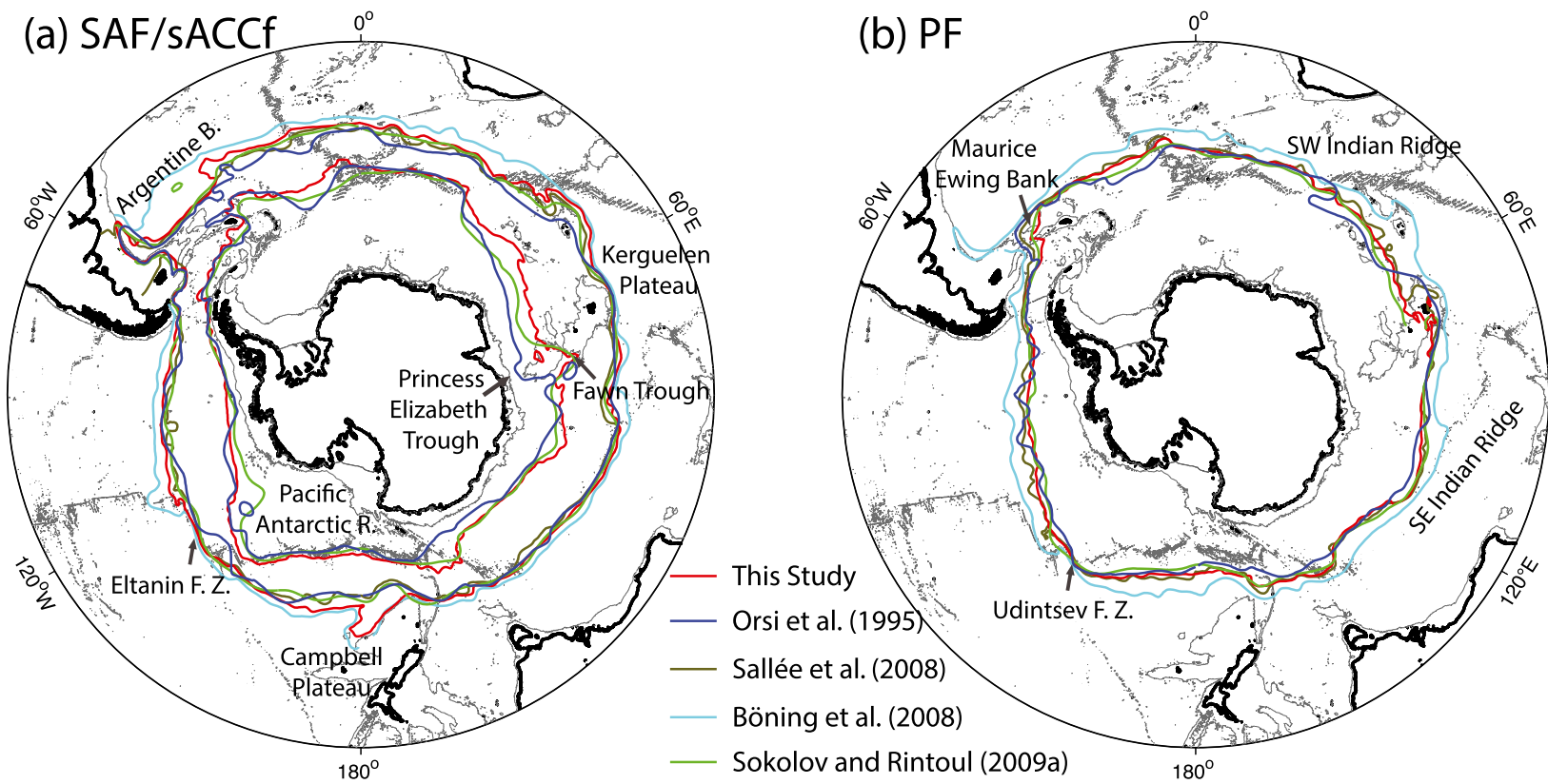

FIG. 6. The climatological distribution of (a) SAF and sACCf and of (b) PF derived from this study (red) vs those that appeared in Orsi et al. (1995; blue), Sokolov and Rintoul (2009a; green), Böning et al. (2008; cyan), and Sallée et al. (2008; olive); the 2500-m isobath (thin gray contour) is included for reference.

and the others indicates the possibility of having two SAF branches in this region (Budillon and Rintoul 2003).

In the vicinity of the Kerguelen Plateau, the SAF paths seem to be tightly constrained by bottom topographies; however, the other frontal paths have been the topics of considerable debate even with in situ hydrographic observations (Orsi et al. 1995; Belkin and Gordon 1996; Sparrow et al. 1996; Roquet et al. 2009; Park et al. 2014). This complexity of frontal locations might be understood in a way whereby the fronts have undergone substantial seasonal fluctuations with a long-term poleward drift. As we will demonstrate in the following section, the southward (northward) excursions of these fronts have been favored during recent (earlier) decades and the austral summer (winter).

The other place showing a substantial divergence is around the Maurice Ewing Bank (see Fig. 6b). Orsi et al. (1995) and Sallée et al. (2008) put the PF at the northern flank of the bank, and Peterson and Whitworth (1989) reported the merging of the SAF and the $\mathrm{PF}$ as staying there based on the Research Vessel (R/V) Melville cruise of 1986. In contrast, Sokolov and Rintoul (2009a) and this study located the path on the southeastern side of this bank. This southern path has been supported by recent intense hydrographic observations by the ALBATROSS 1999 (Naveira Garabato et al. 2002) and JR11 1996 (Trathan et al. 2000) cruises. Naveira Garabato et al. (2002) noted that the PF passes to the south of the bank, and the remnants of a meandering PF pass the northern flank of the bank. Another possibility is that this bifurcation of the PF might be because of its long-term drift to the south. The southwest Atlantic-averaged position of the PF shows a significant poleward drift with a rate of $40 \mathrm{~km} \mathrm{decade}^{-1}$. This rate is probably enough to force the front to move to the southern flank over the course of a few decades.

\section{Variability of the ACC fronts}

\section{a. Spatial variability}

Figure 7 shows how often a streamline passes through each grid point and reveals that the spatial variability of ACC fronts is principally determined by bottom topographies, confirming previous studies (e.g., Gille 1994; Dong et al. 2006; Sallée et al. 2008; Thompson et al. 2010; Langlais et al. 2011; Graham et al. 2012). Over a large topographic feature, a streamline tends to be persistently fixed in a relatively narrow width with a high reoccurrence rate, meaning little temporal variability. The highest reoccurrence rate of up to $80 \%$ was estimated for the SAF looping along the western rim of the $\mathrm{Ar}$ gentine basin $\left(60^{\circ}-54^{\circ} \mathrm{W}\right)$, appearing as a jet with current speed higher than $25 \mathrm{~cm} \mathrm{~s}^{-1}$ at 1000 dbar (see Fig. 5b). Over the northern flank of the Southwest Indian Ridge $\left(0^{\circ}-30^{\circ} \mathrm{E}\right)$, the sACCf was estimated to appear up to $50 \%$ of the time, and similar intense jets associated with the sACCf were also observed along the Pacific-Antarctic 


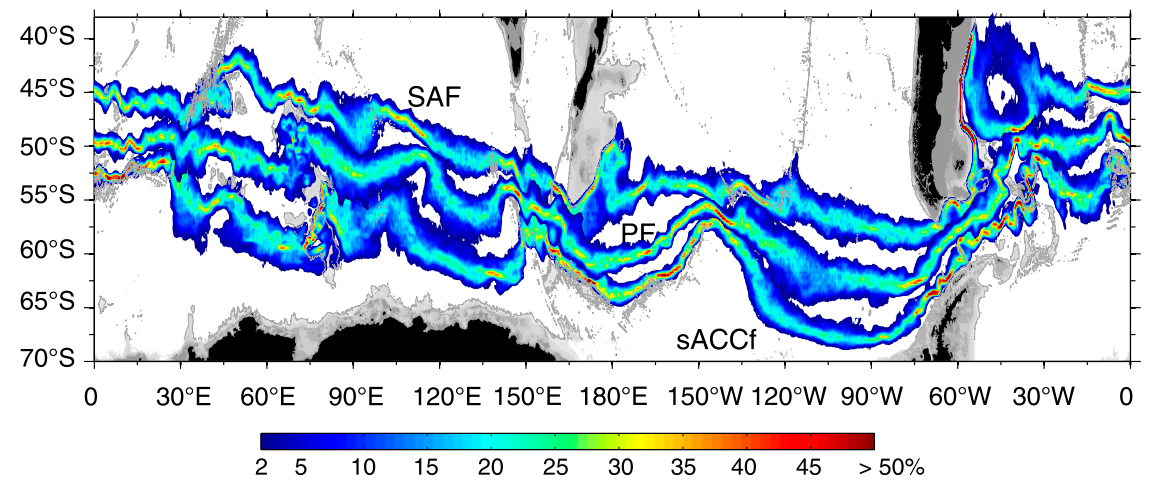

FIG. 7. Distribution of reoccurrence rates (percentage of time) for ACC frontal indicators at grid points where a front was observed at least $2 \%$. Areas shallower than $2500 \mathrm{~m}$ are shaded in gray.

Ridge $\left(150^{\circ}-180^{\circ} \mathrm{W}\right)$. Sharp expressions for the SAF and $\mathrm{PF}$ are also remarkable through the Eltanin and Udintsev Fracture Zones, which are effective cross-ridge gateways to exchange waters between ocean basins (Orsi et al. 1995).

A transition in reoccurrence rates (Fig. 7) is obvious downstream of prominent topographic obstacles (South Scotia Arc and Kerguelen and Campbell Plateaus); the spatial distribution of a streamline becomes greater, with a low reappearance rate, a broad width, and sluggish currents, as these regions are favorable for the production of mesoscale eddies through eddy-mean flow interaction processes (Thompson et al. 2010). When a shallow bottom obstacle steers a front northward because of potential vorticity conservation, instability increases for such a nonzonal flow because of the baroclinic instability process extracting energy from the mean flow. The accumulated baroclinic energies seem to burst out through mesoscale rings within the downstream. There, eddy activity can be a main determining factor for meridional frontal locations. In regions over abyssal plains, where fronts are relatively free from both topographic steering and mesoscale rings, the fronts are expected to have the greatest spatial and temporal variability.

\section{b. Temporal variability}

To infer the temporal variability of ACC fronts in a circumpolar-averaged frame, frontal positions were traced on a weekly basis and then zonally averaged. Displacements, as shown in Fig. 8, were obtained by extracting time-mean latitude from the weekly time series of latitudinal positions for each front. The straight, green line, a long-term linear change estimated from the first-order polynomial fitting, shows that the fronts have experienced substantial poleward drifts; the estimated total drift of the sACCf was $46 \mathrm{~km}$ to the south during the 19-yr period studied, whereas smaller drifts were inferred for the PF $(28 \mathrm{~km})$ and the SAF $(30 \mathrm{~km})$. This observation indicates a broader ACC system over time. These drifts were statistically significant $(p<0.05)$ based on Student's $t$ tests and having magnitudes similar to the observed drifts from previous studies (e.g., Aoki et al. 2005; Sprintall 2008). Note that year-to-year variance, shown as blue lines in Fig. 8, reveals substantial fluctuations identifiable in certain years. During the 1997/98 period, when the strongest El Niño was recorded, for instance, two northernmost fronts experienced
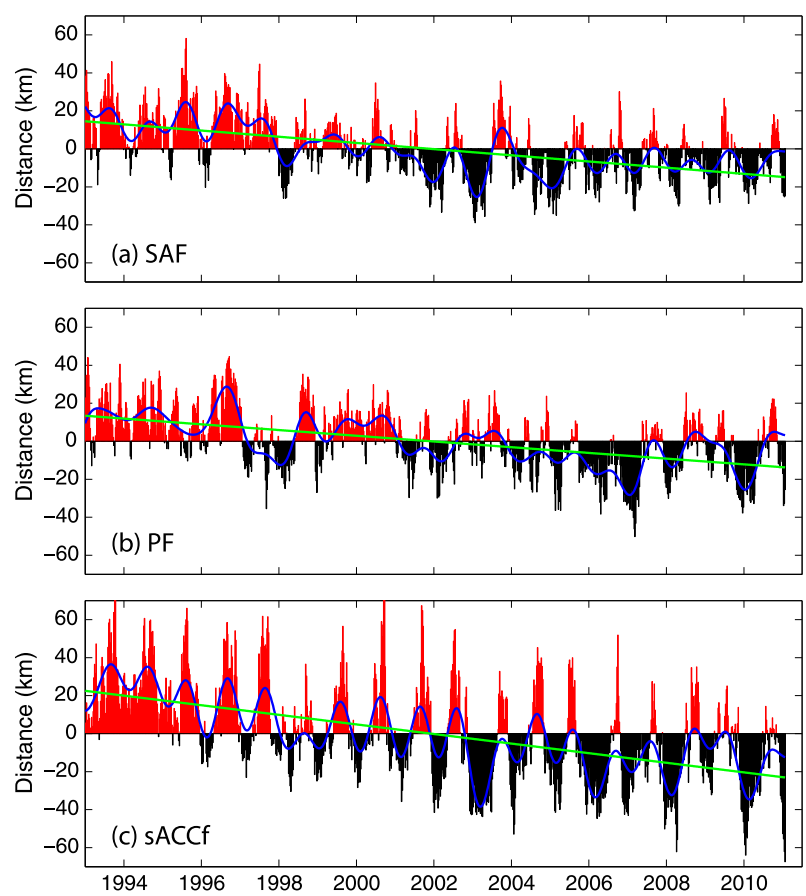

FIG. 8. Weekly time series of the distance between frontal indicators derived from this study to their circumpolar-averaged mean positions for (a) SAF, (b) PF, and (c) sACCf. A positive (red)/negative (black) distance means that a particular front is located equatorward/poleward from its climatological-mean position; the green (blue) lines are their linear trend fits (1-yr low-pass filtered). 

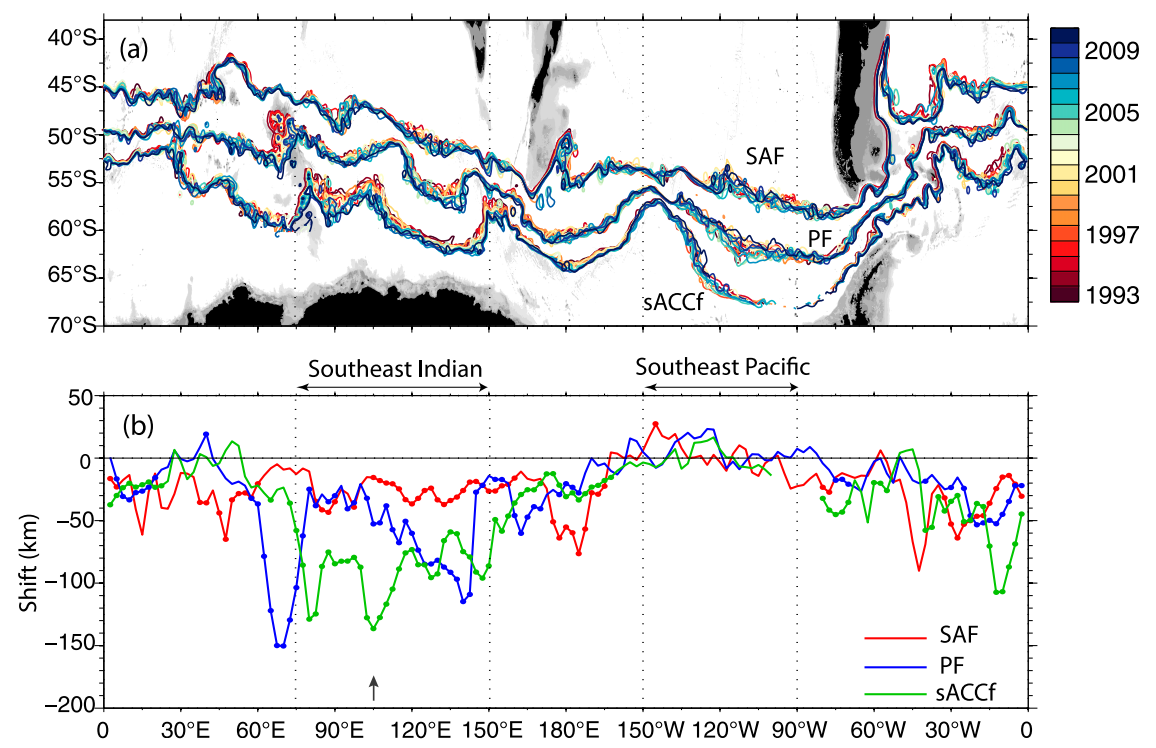

FIG. 9. (a) Annual-mean paths of the ACC fronts from 1993 to 2010 and (b) estimated total drifts assuming linear trends. The dots show statistically significant drifts with values above the $95 \%$ confidence level using Student's $t$ test. The black arrow in (b) indicates the longitude $\left(105^{\circ} \mathrm{E}\right)$ with significant drifts investigated in Fig. 3a. Areas shallower than $2500 \mathrm{~m}$ are shaded in gray.

noticeable southward displacements. This interannual fluctuation possibly represents the influence of ENSO on meridional frontal positions, as we will discuss in the following section.

While circumpolar-averaged frontal paths have showed significant poleward trends during the last two decades, these long-term changes are not zonally symmetric, but highly localized (Fig. 9). Within the southeast Indian $\left(75^{\circ}-150^{\circ} \mathrm{E}\right)$, the two southernmost fronts showed substantial poleward drifts, ranging from around 100 to $400 \mathrm{~km}$ based on yearly mean frontal paths as illustrated in Fig. 9a. When applying the firstorder least squares fitting to weekly SSH data along longitudes, smaller but statistically significant drifts were estimated for this sector (Fig. 9b). Those poleward movements are opposite those estimated by Graham et al. (2012) using a $\mathrm{CO}_{2}$ quadrupling simulation, which postulated that the simulated equatorward shift of the ACC is a response to the expansion of a subpolar gyre caused by enhanced northward Ekman transport because of intensified westerlies. This numerical experiment, however, hints that there is a possibility of the frontal positions in this sector being mainly controlled by the relative strength of subtropical and subpolar gyres. Smaller, but still statistically significant, drifts to the south, have also been inferred downstream of the South Scotia Arc in the southeast Atlantic $\left(45^{\circ} \mathrm{W}-20^{\circ} \mathrm{E}\right)$.

In contrast to these sectors, the southeast Pacific $\left(150^{\circ}-90^{\circ} \mathrm{W}\right)$ shows unique frontal behavior with considerable fluctuations in latitudinal locations (Fig. 9a).
However, these fluctuations do not render an apparent long-term trend (see Fig. 9b). This lack of a long-term shift is contrary to what many might expect for this sector with a flat basin, but is consistent with a numerical simulation (Graham et al. 2012). This finding indicates that the long-term frontal drifts, as shown in Fig. 8 and in previous studies (e.g., Gille 2008; Böning et al. 2008; Sokolov and Rintoul 2009b), might be a very localized feature in the Indian and Atlantic sectors and thus less representative of the entire ACC.

An inspection of Fig. 9 suggests a noticeable seasonal cycle in all frontal locations on the circumpolaraveraged frame. To capture localized seasonal patterns, we applied a harmonic analysis to the weekly SSH data at each longitude, revealing that seasonality is spatially localized, the same as in long-term trends (Fig. 10). While in most of the circumpolar regions the amplitude of seasonality is less than $10 \mathrm{~km}$ as noted by Graham and De Boer (2013), large seasonal fluctuations have been indicated in the Atlantic $\left(55^{\circ}-25^{\circ} \mathrm{W}\right)$ and Indian $\left(60^{\circ}-120^{\circ} \mathrm{E}\right)$ sectors. This localized seasonality is in agreement with the results of Dong et al. (2006), who tracked the PF based on enhanced sea surface temperature gradients.

\section{c. Responses to atmospheric changes}

Figure 11 shows the correlation coefficients between the meridional positions of the ACC fronts and atmospheric variabilities. Following Sallée et al. (2008), we applied a similar approach, except we filtered out 


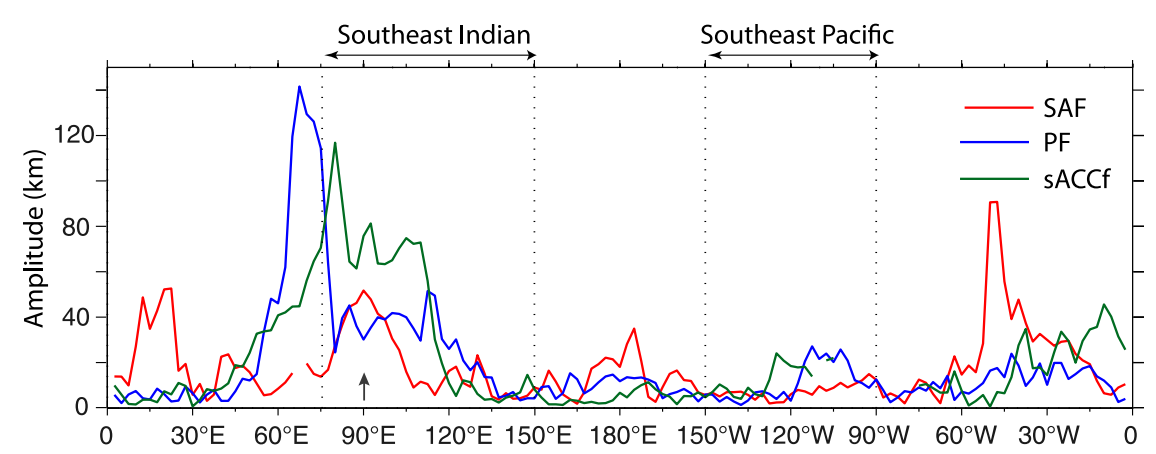

FIG. 10. Peak-to-peak amplitude of annual frontal cycles for the ACC fronts estimated using the harmonic analysis. The black arrow indicates the location $\left(90^{\circ} \mathrm{E}\right)$ with significant seasonality investigated in Fig. 3b.

high-frequency signals by using a 1-yr Butterworth window to concentrate on year-to-year frontal variability. Not surprisingly, the overall correlation pattern was similar to the results of Sallée et al. (2008, see their Figs. 11a and 12a), with distinct localized patterns between the southeast Pacific $\left(150^{\circ}-90^{\circ} \mathrm{W}\right)$ and southeast Indian $\left(75^{\circ}-150^{\circ} \mathrm{E}\right)$.

The frontal positions within the southeast Pacific, previously characterized by substantial fluctuations without any long-term trend and seasonality, showed considerable responses to SAM and ENSO; the fronts tend to drift northward (southward) during +SAM or -ENSO $(-\mathrm{SAM}$ or $+\mathrm{ENSO})$. The PF showed the largest responses to the atmospheric variabilities: its correlation coefficient was up to -0.8 with ENSO and had a slightly smaller coefficient of 0.55 with SAM. These correlations have some important implications for changes in the meridional positions of the PF: (i) the ENSO and SAM
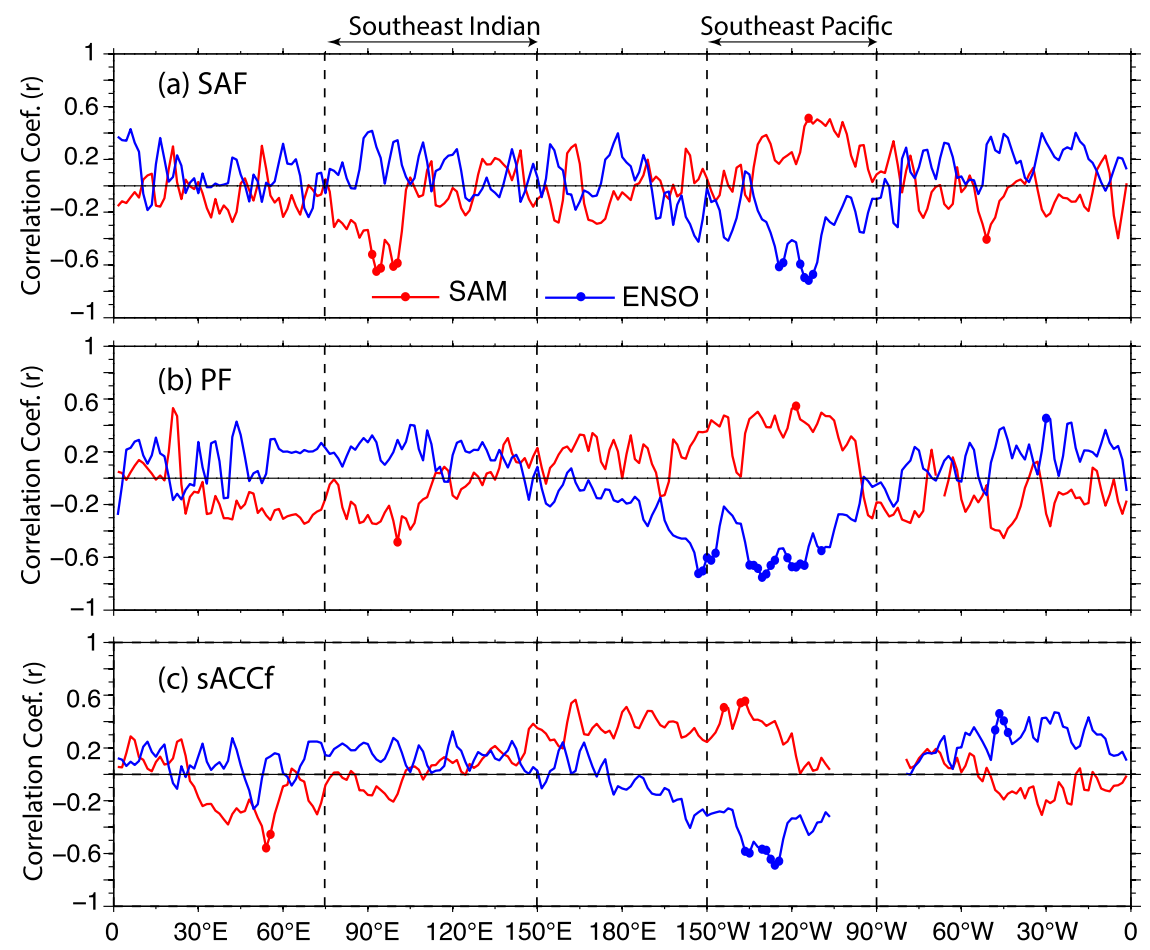

FIG. 11. Zonal distribution of correlation coefficients between the meridional displacements of the ACC fronts with the SAM (red) and ENSO (blue) indices. The large dots indicate values statistically significant above the $95 \%$ confidence level using Student's $t$ test. A positive (negative) correlation indicates northward (southward) displacement of the fronts in response to interannual atmospheric variability. 


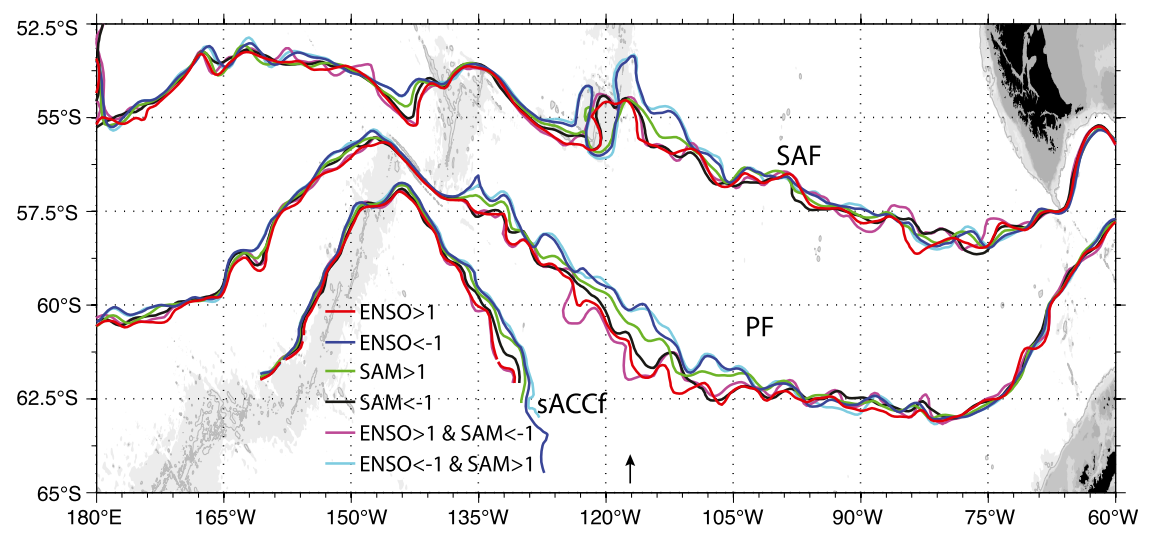

FIG. 12. Mean location of the ACC fronts for particular periods categorized into \pm 1 of the SAM and ENSO indices. The black arrow indicates a longitude of $117^{\circ} \mathrm{W}$ with substantial fluctuations investigated in Fig. 3c. Areas shallower than $2500 \mathrm{~m}$ are shaded in gray.

indices can account for up to $64 \%$ and $30 \%$, respectively, implying that both indices likely explain most of the year-to-year meridional variance of this front on the assumption that these indices are statistically independent (Verdy et al. 2006; Vivier et al. 2010); (ii) thus, we can expect most northward (southward) frontal positions when La Niña (El Niño) occurs during positive (negative) SAM periods; however, (iii) ENSO shows further impacts on the meridional positions of the ACC than SAM. Figure 12 illustrates the mean frontal locations for specific periods categorized into \pm 1 of the SAM and ENSO indices, supporting these implications. The largest displacement of up to $2^{\circ}(\sim 220 \mathrm{~km})$ was observed for the $\mathrm{PF}$ at around $117^{\circ} \mathrm{W}$ between $-\mathrm{ENSO} /+\mathrm{SAM}$ and $+\mathrm{ENSO} /-\mathrm{SAM}$ periods. Also, Fig. 12 confirms a dominant ENSO contribution to frontal positions; the fronts during opposite sign combinations [+ENSO/-SAM (the purple contour in Fig. 12) and -ENSO/+SAM (cyan)] do not show significant differences from the positions only for El Niño (red) or La Niña (blue). Note that even though the atmospheric variabilities strongly affect the PF in this sector, there is a sharp drop in the correlation coefficient near $140^{\circ} \mathrm{W}$ (Figs. 11, 12), at which the PF flows through the Udintsev Fracture Zone, reminding us that fronts are almost fixed over such a large topographical feature.

In contrast to the Pacific, there is no significant relationship between the interannual frontal positions and atmospheric variabilities in the southeast Indian (Fig. 11), implying that the long-term poleward drifts estimated in this sector might be not directly results of atmospheric variabilities. One exception is the SAF in a narrowband between $90^{\circ}$ and $100^{\circ} \mathrm{E}$, where the SAF tends to move southward during positive SAM periods.

\section{Mechanisms for localized responses}

\section{a. Southeast Pacific: Anomalous Ekman transport}

Unique frontal behaviors within the southeast Pacific, substantial fluctuations without any long-term trend, and seasonality are consistent with other independent satellite datasets including the AVHRR-based SST (Reynolds et al. 2007) and the sea ice extent (Comiso 2012). Monthly SST anomalies after removing seasonal cycles were averaged over the southeast Pacific $\left(50^{\circ}-\right.$ $67.5^{\circ} \mathrm{S}, 150^{\circ}-90^{\circ} \mathrm{W}$ ) and then $1-\mathrm{yr}$ low-pass filtering was applied to focus on the year-to-year variance. To investigate the contributions of ENSO and SAM to the observed SST anomaly, we did a bivariate regression analysis with 2-month preceding atmospheric indices based on the least squares fitting approach. The 2-month lag was selected because the correlation coefficients between the observed and calculated SST shows its maximum with this lag, indicating that around 2 months are needed for the SST to fully adjust to atmospheric changes. This delayed response is also consistent with a 7-week lag between atmospheric changes and the accompanying SST responses (Vivier et al. 2010).

It is significant that the time series of SST anomalies averaged over the southeast Pacific also showed substantial fluctuations with a negligible trend (Fig. 13a). There, the correlation coefficient between the observed and regressed SST anomalies was 0.8, meaning that SAM and ENSO together account for about $64 \%$ of the year-to-year SST anomaly variance. This result confirms that this sector is largely sensitive to atmospheric changes, as depicted above in the relationship between the fronts and atmospheric indices. Consistent with the SST, the time series of the September sea ice extent in this sector $\left(150^{\circ}-90^{\circ} \mathrm{W}\right)$ has also showed a substantial fluctuation without any significant trend during the last three decades (Fig. 13c). 

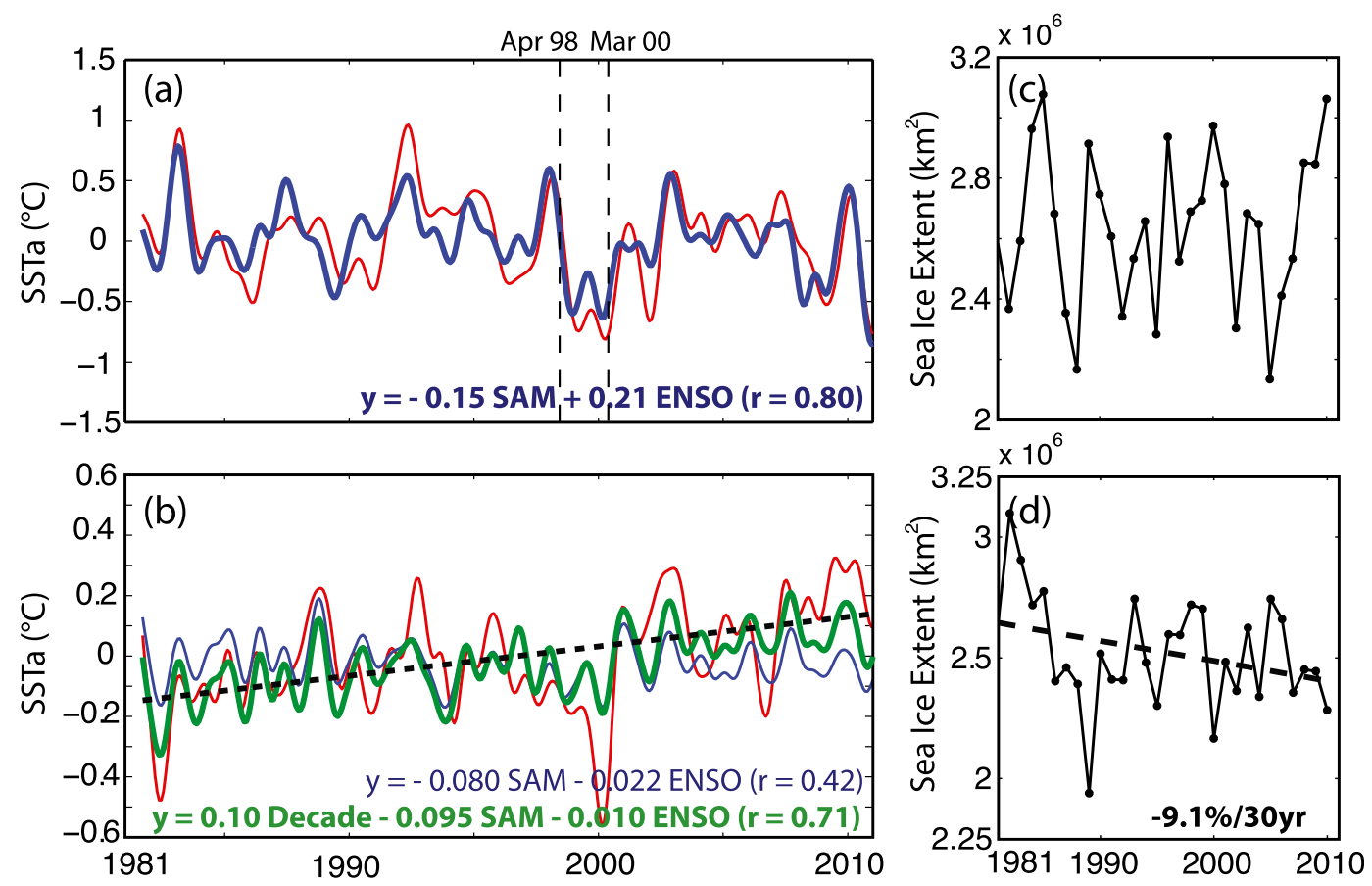

FIG. 13. Time series of (a),(b) SST anomalies and (c),(d) September sea ice extents (sum of areas containing at least $15 \%$ of sea ice concentration) over the (top) southeast Pacific $\left(50^{\circ}-67.5^{\circ} \mathrm{S}, 150^{\circ}-90^{\circ} \mathrm{W}\right)$ and (bottom) southeast Indian $\left(45^{\circ}-62.5^{\circ} \mathrm{S}, 75^{\circ}-150^{\circ} \mathrm{E}\right)$ oceans. SST anomalies are regionally averaged and filtered with a 1-yr low-pass window (red lines). Regressed SST anomalies are based on least squares fitting using 2-month-preceded atmospheric indices (blue lines). A regressed SST anomaly including the long-term linear trend is illustrated as a green line (and corresponding equation). Values of $r$ are the correlation coefficients between the observed and regressed time series. The long-term linear trends in SST anomalies and September sea ice concentration are indicated as dashed lines in (b) and (d), respectively. The vertical lines in (a) indicate the period between April 1998 and March 2000, when La Niña case $($ ENSO $<-1)$ coincidently happened with a positive SAM $($ SAM $>+1)$.

One mechanism controlling these characteristic oceanic variabilities within this sector might be an anomalous Ekman transport, as suggested by Sallée et al. (2008). The Ekman anomaly associated with SAM and ENSO shows a localized structure characterized by a meridionally elongated distribution to midlatitudes in the Pacific; this spatial distribution is out-of-phase for SAM and ENSO. For instance, during positive SAM or La Niña periods, a prominent northward Ekman transport could steer the ACC to the north and bring cold subpolar waters up to midlatitudes. The spatially out-of-phase pattern in Ekman transport anomalies between SAM and ENSO hints that a concurrence of opposite sign combinations (i.e., $+\mathrm{SAM} /-\mathrm{ENSO}$ and $-\mathrm{SAM} /+\mathrm{ENSO}$ ) would reinforce oceanic responses as partially proved in Fig. 12. When a La Niña (ENSO $<-1$ ) event occurs with a positive SAM (SAM $>1)$, positive overlapping Ekman transport anomalies could push fronts farther north, supplying more cold subpolar waters to midlatitudes and finally resulting in abnormal cooling in this sector. This process seems to account for the substantial cooling recorded during April 1998 and March 2000 (these periods are indicated as dashed lines in Fig. 13a), when one of the strongest recorded La Niña events occurred during positive SAM periods.

\section{b. Southeast Indian: Poleward expansion of the Indian subtropical gyre}

In contrast to the southeast Pacific, atmospheric variabilities through anomalous Ekman transport seem to fail to explain the basin-scale poleward drift of the ACC observed in the southeast Indian. As shown by Sallee et al. (2008), a positive SAM tends to cause the SAF to move toward the pole in this sector; however, it is insignificant or too localized around $95^{\circ} \mathrm{E}$ to explain this basin-scale drift. A similar situation is found for the averaged SST anomalies over this sector $\left(45^{\circ}-62.5^{\circ} \mathrm{S}\right.$ and $75^{\circ}-150^{\circ} \mathrm{E}$; see Fig. $13 \mathrm{~b}$ ). Here, both the SAM and ENSO indices account for only $18 \%\left(0.42^{2}\right)$ of SST interannual variance. However, when considering the long-term warming trend of $0.10^{\circ} \mathrm{Cdecade}^{-1}$, a correlation coefficient between the observed (the red line in Fig. 13b) and the regressed SST anomalies (the green line) reaches up to 0.71 . In agreement with this warming 
trend, the winter sea ice extent within this sector $\left(75^{\circ}-\right.$ $\left.150^{\circ} \mathrm{E}\right)$ has experienced considerable shrinking of around $9.1 \%\left(-8.3 \times 10^{3} \mathrm{~km}^{2} \mathrm{yr}^{-1}\right)$ over the past 3 decades (Fig. 13d), which may be an indication that the ACC in this sector has moved poleward. This shrinking is sharply contrasted with the slight but significant increasing sea ice trend of $2.0 \times 10^{4} \mathrm{~km}^{2} \mathrm{yr}^{-1}$ (a total $3.1 \%$ increase over three decades) throughout the Southern Ocean (not shown), suggesting that there might be localized ocean dynamics controlling this sector.

An alternative dynamic that could potentially contribute to the observed oceanic changes is the intensification and poleward expansion of the Indian subtropical gyre, as suggested by previous studies (Biastoch et al. 2009; Rouault et al. 2009; Wang et al. 2011; Graham et al. 2012; Wu et al. 2012). According to Wu et al. (2012), the Agulhas system region has warmed, which is associated with the intensification of the western boundary current during multiple decades. The enhanced inertia of the Agulhas Current works in tandem with the concurrent poleward shift of a zero wind stress curl over the Indian Ocean (Biastoch et al. 2009) and then constitutes a favorable condition for the poleward expansion of the gyre (de Ruijter et al. 1999). Bottom topographies seem to play an important role in limiting a sector (de Boer et al. 2013). In the case of the western Indian, complex topographies with ridges and rises likely delimit the southern boundary of the subtropical gyre by steering the Agulhas Return Current. The eastern sector, however, has relatively weak topographical constraints on this current, allowing the subtropical gyre to expand easily. Through this gate, the persistent expansion of the subtropical gyre seems to dynamically push the ACC system toward the south, resulting in the poleward drift of the ACC, SST warming, and sea ice shrinking in this sector. Note that the localized frontal seasonality in analogy with long-term drifts in this sector allows us to deduce that the same mechanism might be applicable to understanding this seasonality; that the gyre tends to expand to the south during the austral summer and then retreat to the north during the winter (Ffield et al. 1997) might relate to the observed frontal seasonality in this sector. However, a refined mechanism controlling the seasonality of fronts needs further study.

\section{Conclusions}

While ACC frontal distributions in areas with complex bathymetry are mainly topographically controlled, this study reveals a highly contrasting variability pattern over large abyssal plains; a substantial year-to-year fluctuation is indicated in the southeast Pacific, whereas long-term poleward drifts and seasonality are apparent in the southeast Indian. This fluctuation in the Pacific is largely explained by dominant atmospheric variabilities through anomalous Ekman transport, suggesting that this sector could have experienced a northward (southward) shift of the ACC during - ENSO or + SAM (+ENSO or - SAM) periods with major contribution from ENSO. Elsewhere along most of the circumpolar regime, the correlation between ACC frontal variability and the westerlies is statistically insignificant—opposite the previous reports attributing the southward shifts of the ACC system to intensified westerly winds. Indian frontal variability is driven by regional changes in oceanic circulation. We believe that the poleward drift of the ACC in this sector may be a dynamical response to the observed expansion and intensification of the Indian subtropical gyre.

Such contrasting frontal variabilities would make it difficult to detect a climate signal in the Southern Ocean on a circumpolar-averaged framework. Thus, we suggest that analyses on regional ocean circulation could help a comprehensive understanding of ACC frontal variabilities and the underlying mechanisms. Prominent regional contrasts in ACC frontal variability warrant further studies of localized responses to climate signals and smaller-scale forcing.

Acknowledgments. The authors thank two anonymous reviewers for their helpful comments. As part of Yong Sun Kim's graduate research at Texas A\&M University, this work was supported by the National Science Foundation (under the ANT-0839005 and OCE-0961523 grants). Yong Sun Kim also appreciates the helpful discussions with Dr. Chan Joo Jang and Dr. Ho-Jeong Shin during the revision of this paper and was supported by the Korea Institute of Ocean Science and Technology (under the PE99271 and PE99231 grants) and the Professional Human Resource Training Project of Korea Maritime and Ocean University in the KMOU-KIOST Ocean Science and Technology.

\section{REFERENCES}

Aoki, S., N. L. Bindoff, and J. A. Church, 2005: Interdecadal water mass changes in the Southern Ocean between $30^{\circ} \mathrm{E}$ and $160^{\circ} \mathrm{E}$. Geophys. Res. Lett., 32, L07607, doi:10.1029/2004GL022220.

AVISO, 2009: SSALTO/DUACS user handbook: (M)SLA and (M)ADT near-real time and delayed time products. CLSDOS-NT-06.034 Rep., 34 pp.

Barré, N., C. Provost, A. Renault, and N. Sennéchael, 2011: Fronts, meanders, and eddies in Drake Passage during the ANTXXIII/3 cruise in January-February 2006: A satellite perspective. Deep-Sea Res. II, 58, 2533-2554, doi:10.1016/ j.dsr2.2011.01.003.

Belkin, I. M., and A. L. Gordon, 1996: Southern Ocean fronts from the Greenwich meridian to Tasmania. J. Geophys. Res., 101, 3675-3696, doi:10.1029/95JC02750. 
Biastoch, A., C. W. Böning, F. U. Schwarzkopf, and J. R. E. Lutjeharms, 2009: Increase in Agulhas leakage due to poleward shift of Southern Hemisphere westerlies. Nature, 462, 495-498, doi:101038/nature08519.

Billany, W., S. Swart, J. Hermes, and C. J. C. Reason, 2010: Variability of the Southern Ocean fronts at the Greenwich meridian. J. Mar. Syst., 82, 304-310, doi:10.1016/j.jmarsys.2010.06.005.

Böning, C. W., A. Dispert, M. Visbeck, S. R. Rintoul, and F. U. Schwarzkopf, 2008: The response of the Antarctic Circumpolar Current to recent climate change. Nat. Geosci., 1, 864869, doi:10.1038/ngeo362.

Budillon, G., and S. R. Rintoul, 2003: Fronts and upper ocean thermal variability south of New Zealand. Antarct. Sci., 15, 141-152, doi:10.1017/S0954102003001135.

Chapman, C. C., 2014: Southern Ocean jets and how to find them: Improving and comparing common jet detection methods. J. Geophys. Res. Oceans, 119, 4318-4339, doi:10.1002/ 2014JC009810.

Chereskin, T. K., K. A. Donohue, D. R. Watts, K. L. Tracey, Y. L. Firing, and A. L. Cutting, 2009: Strong bottom currents and cyclogenesis in Drake Passage. Geophys. Res. Lett., 36, L23602, doi:10.1029/2009GL040940.

Comiso, J. C., 2012: Bootstrap sea ice concentrations from Nimbus-7 SMMR and DMSP SSM/I-SSMIS, version 2. National Snow and Ice Data Center, Boulder, CO, digital media. [Available online at http://nsidc.org/data/docs/daac/nsidc0079_bootstrap_ seaice.gd.html.]

Cunningham, S. A., and M. Pavic, 2007: Surface geostrophic currents across the Antarctic Circumpolar Current in Drake Passage from 1992 to 2004. Prog. Oceanogr., 73, 296-310, doi:10.1016/j.pocean.2006.07.010.

de Boer, A. M., R. M. Graham, M. D. Thomas, and K. E. Kohfeld, 2013: The control of the Southern Hemisphere westerlies on the position of the Subtropical Front. J. Geophys. Res. Oceans, 118, 5669-5675, doi:10.1002/jgrc.20407.

de Ruijter, W. P. M., A. Biastoch, S. S. Drijfhout, J. R. E. Lutjeharms, R. P. Matano, T. Pichevin, P. J. van Leeuwen, and W. Weijer, 1999: Indian-Atlantic interocean exchange: Dynamics, estimation and impact. J. Geophys. Res., 104, 20885 20 910, doi:10.1029/1998JC900099.

Dong, S. F., J. Sprintall, and S. T. Gille, 2006: Location of the Antarctic Polar Front from AMSR-E satellite sea surface temperature measurements. J. Phys. Oceanogr., 36, 20752089, doi:10.1175/JPO2973.1.

Ducet, N., and P. Y. Le Traon, 2001: A comparison of surface eddy kinetic energy and Reynolds stresses in the Gulf Stream and the Kuroshio current systems from merged TOPEX/Poseidon and ERS-1/2 altimetric data. J. Geophys. Res., 106, 1660316 622, doi:10.1029/2000JC000205.

Ffield, A., J. Toole, and D. Wilson, 1997: Seasonal circulation in the south Indian Ocean. Geophys. Res. Lett., 24, 2773-2776, doi:10.1029/97GL01253.

Fukamachi, Y., S. R. Rintoul, J. A. Church, S. Aoki, S. Sokolov, M. A. Rosenberg, and M. Wakatsuchi, 2010: Strong export of Antarctic Bottom Water east of the Kerguelen Plateau. Nat. Geosci., 3, 327-331, doi:10.1038/ngeo842.

Gille, S. T., 1994: Mean sea surface height of the Antarctic Circumpolar Current from Geosat data: Method and application. J. Geophys. Res., 99, 18255-18273, doi:10.1029/ 94JC01172.

— 2008: Decadal-scale temperature trends in the Southern Hemisphere ocean. J. Climate, 21, 4749-4765, doi:10.1175/ 2008JCLI2131.1.
- 2014: Meridional displacement of the Antarctic Circumpolar Current. Philos. Trans. Roy. Soc. London, A372, 20130273, doi:10.1098/rsta.2013.0273.

Gordon, A. L., 1975: An Antarctic oceanographic section along $170^{\circ}$ E. Deep-Sea Res. Oceanogr. Abstr., 22, 357-377, doi:10.1016/ 0011-7471(75)90060-1.

Graham, R. M., and A. M. de Boer, 2013: The dynamical Subtropical Front. J. Geophys. Res. Oceans, 118, 5676-5685, doi:10.1002/jgrc.20408.

,-- K. J. Heywood, M. R. Chapman, and D. P. Stevens, 2012: Southern Ocean fronts: Controlled by wind or topography? J. Geophys. Res., 117, C08018, doi:10.1029/ 2012JC007887.

Langlais, C., S. Rintoul, and A. Schiller, 2011: Variability and mesoscale activity of the Southern Ocean fronts: Identification of a circumpolar coordinate system. Ocean Modell., 39, 79-96, doi:10.1016/j.ocemod.2011.04.010.

Lee, T., and Coauthors, 2010: Record warming in the South Pacific and western Antarctica associated with the strong centralPacific El Niño in 2009-10. Geophys. Res. Lett., 37, L19704, doi:10.1029/2010GL044865.

Lenn, Y. D., T. K. Chereskin, J. Sprintall, and E. Firing, 2007: Mean jets, mesoscale variability and eddy momentum fluxes in the surface layer of the Antarctic Circumpolar Current in Drake Passage. J. Mar. Res., 65, 27-58, doi:10.1357/ 002224007780388694.

Liu, J., and J. A. Curry, 2010: Accelerated warming of the Southern Ocean and its impacts on the hydrological cycle and sea ice. Proc. Natl. Acad. Sci. USA, 107, 14987-14 992, doi:10.1073/ pnas.1003336107.

Marshall, G. J., 2003: Trends in the southern annular mode from observations and reanalyses. J. Climate, 16, 4134-4143, doi:10.1175/1520-0442(2003)016<4134:TITSAM>2.0.CO;2.

Meijers, A. J. S., E. Shuckburgh, N. Bruneau, J.-B. Sallée, T. J. Bracegirdle, and Z. Wang, 2012: Representation of the Antarctic Circumpolar Current in the CMIP5 climate models and future changes under warming scenarios. J. Geophys. Res., 117, C12008, doi:10.1029/2012JC008412.

Morrison, A. K., and A. Hogg, 2013: On the relationship between Southern Ocean overturning and ACC transport. J. Phys. Oceanogr., 43, 140-148, doi:10.1175/JPO-D-12-057.1.

Naveira Garabato, A. C., E. L. McDonagh, D. P. Stevens, K. J. Heywood, and R. J. Sanders, 2002: On the export of Antarctic Bottom Water from the Weddell Sea. Deep-Sea Res., 49, 47154742, doi:10.1016/S0967-0645(02)00156-X.

- , L. Jullion, D. P. Stevens, K. J. Heywood, and B. A. King, 2009: Variability of Subantarctic Mode Water and Antarctic Intermediate Water in the Drake Passage during the latetwentieth and early-twenty-first centuries. J. Climate, 22, 3661-3688, doi:10.1175/2009JCLI2621.1.

- R. Ferrari, and K. L. Polzin, 2011: Eddy stirring in the Southern Ocean. J. Geophys. Res., 116, C09019, doi:10.1029/ 2010JC006818.

Nowlin, W. D., and M. Clifford, 1982: The kinematic and thermohaline zonation of the Antarctic Circumpolar Current at Drake Passage. J. Mar. Res., 40, 481-507.

Orsi, A. H., T. Whitworth, and W. D. Nowlin, 1995: On the meridional extent and fronts of the Antarctic Circumpolar Current. Deep-Sea Res., 42, 641-673, doi:10.1016/ 0967-0637(95)00021-W.

_ G. C. Johnson, and J. L. Bullister, 1999: Circulation, mixing, and production of Antarctic Bottom Water. Prog. Oceanogr., 43, 55-109, doi:10.1016/S0079-6611(99)00004-X. 
Park, J. J., K. Kim, B. A. King, and S. C. Riser, 2005: An advanced method to estimate deep currents from profiling floats. J. Atmos. Oceanic Technol., 22, 1294-1304, doi:10.1175/ JTECH1748.1.

Park, Y.-H., F. Vivier, F. Roquet, and E. Kestenare, 2009: Direct observations of the ACC transport across the Kerguelen Plateau. Geophys. Res. Lett., 36, L18603, doi:10.1029/ 2009GL039617.

— I. Iurand, E. Kestenare, G. Rougier, M. Zhou, F. d'Ovidio, C. Cotté, and J.-H. Lee, 2014: Polar Front around the Kerguelen Islands: An up-to-date determination and associated circulation of surface/subsurface waters. J. Geophys. Res. Oceans, 119, doi:10.1002/2014JC010061.

Peterson, R. G., and T. Whitworth, 1989: The Subantarctic and Polar Fronts in relation to deep water masses through the southwestern Atlantic. J. Geophys. Res., 94, 10817-10838, doi:10.1029/JC094iC08p10817.

Renault, A., C. Provost, N. Sennéchael, N. Barré, and A. Kartavtseff, 2011: Two full depth velocity sections in the Drake Passage in 2006-Transport estimates. Deep-Sea Res. II, 58, 2572-2591, doi:10.1016/j.dsr2.2011.01.004.

Reynolds, R. W., T. M. Smith, C. Liu, D. B. Chelton, K. S. Casey, and M. G. Schlax, 2007: Daily high-resolution-blended analyses for sea surface temperature. J. Climate, 20, 5473-5496, doi:10.1175/2007JCLI1824.1.

Rio, M.-H., and F. Hernandez, 2004: A mean dynamic topography computed over the world ocean from altimetry, in-situ measurements, and a geoid model. J. Geophys. Res., 109, C12032, doi:10.1029/2003JC002226.

, P. Schaeffer, G. Moreaux, J.-M. Lemoine, and E. Bronner, 2009: A new mean dynamic topography computed over the global ocean from GRACE data, altimetry and in-situ measurements. Proc. OceanObs'09, Venice, Italy, IOC/UNESCO and ESA. [Available online at http://www.aviso.oceanobs. com/fileadmin/documents/data/products/auxiliary/MDT_CnesCLS09_poster_Oceanobs09.pdf.]

Rodman, M. R., and A. L. Gordon, 1982: Southern Ocean bottom water of the Australian-New Zealand sector. J. Geophys. Res., 87, 5771-5778, doi:10.1029/JC087iC08p05771.

Roquet, F., Y.-H. Park, C. Guinet, F. Bailleul, and J.-B. Charrassin, 2009: Observations of the Fawn Trough Current over the Kerguelen Plateau from instrumented elephant seals. J. Mar. Syst., 78, 377-393, doi:10.1016/j.jmarsys.2008.11.017.

Rouault, M., P. Penven, and B. Bohl, 2009: Warming in the Agulhas Current system since the 1980's. Geophys. Res. Lett., 36, L12602, doi:10.1029/2009GL037987.

Sallée, J.-B., K. Speer, and R. Morrow, 2008: Response of the Antarctic Circumpolar Current to atmospheric variability. J. Climate, 21, 3020-3039, doi:10.1175/2007JCLI1702.1.

Sloyan, B. M., and S. R. Rintoul, 2001: The Southern Ocean limb of the global deep overturning circulation. J. Phys. Oceanogr., 31, 143-173, doi:10.1175/1520-0485(2001)031<0143: TSOLOT $>2.0 . \mathrm{CO} ; 2$.

Smith, C. A., and P. D. Sardeshmukh, 2000: The effect of ENSO on the intraseasonal variance of surface temperature in winter. Int. J. Climatol., 20, 1543-1557, doi:10.1002/ 1097-0088(20001115)20:13<1543::AID-JOC579>3.0.CO;2-A.

Sokolov, S., and S. R. Rintoul, 2002: Structure of Southern Ocean fronts at $140^{\circ}$ E. J. Mar. Syst., 37, 151-184, doi:10.1016/ S0924-7963(02)00200-2.

, and - 2007: Multiple jets of the Antarctic Circumpolar Current South of Australia. J. Phys. Oceanogr., 37, 1394-1412, doi:10.1175/JPO3111.1.
— and —, 2009a: Circumpolar structure and distribution of the Antarctic Circumpolar Current fronts: 1. Mean circumpolar paths. J. Geophys. Res., 114, C11018, doi:10.1029/ 2008JC005108.

$\longrightarrow$, and - 2009b: Circumpolar structure and distribution of the Antarctic Circumpolar Current fronts: 2. Variability and relationship to sea surface height. J. Geophys. Res., 114, C11019, doi:10.1029/2008JC005248.

Sparrow, M. D., K. J. Heywood, J. Brown, and D. P. Stevens, 1996: Current structure of the south Indian Ocean. J. Geophys. Res., 101, 6377-6391, doi:10.1029/95JC03750.

Sprintall, J., 2003: Subsurface structure of interannual temperature anomalies in the Australian sector of the Southern Ocean J. Geophys. Res., 108, 3285, doi:10.1029/2002JC001494.

2008: Long-term trends and interannual variability of temperature in Drake Passage. Prog. Oceanogr., 77, 316-330, doi:10.1016/j.pocean.2006.06.004.

Swart, N. C., and J. C. Fyfe, 2012: Observed and simulated changes in the Southern Hemisphere surface westerly wind-stress. Geophys. Res. Lett., 39, L16711, doi:10.1029/ 2012GL052810.

Swart, S., S. Speich, I. J. Ansorge, and J. R. E. Lutjeharms, 2010: An altimetry-based gravest empirical mode south of Africa: 1. Development and validation. J. Geophys. Res., 115, C03002, doi:10.1029/2009JC005299.

Thompson, A. F., and J.-B. Sallée, 2012: Jets and topography: Jet transitions and the impact on transport in the Antarctic Circumpolar Current. J. Phys. Oceanogr., 42, 956-972, doi:10.1175/ JPO-D-11-0135.1.

_ P. H. Haynes, C. Wilson, and K. J. Richards, 2010: Rapid Southern Ocean front transitions in an eddy-resolving ocean GCM. Geophys. Res. Lett., 37, L23602, doi:10.1029/2010GL045386.

Thorpe, S. E., K. J. Heywood, M. A. Brandon, and D. P. Stevens, 2002: Variability of the southern Antarctic Circumpolar Current Front north of south Georgia. J. Mar. Syst., 37, 87-105, doi:10.1016/S0924-7963(02)00197-5.

Tilburg, C. E., H. E. Hurlburt, J. J. O'Brien, and J. F. Shriver, 2002: Remote topographic forcing of a baroclinic western boundary current: An explanation for the Southland Current and the pathway of the Subtropical Front east of New Zealand. J. Phys. Oceanogr., 32, 3216-3232, doi:10.1175/ 1520-0485(2002)032<3216:RTFOAB $>2.0 . \mathrm{CO} ; 2$.

Toggweiler, J. R., and J. Russell, 2008: Ocean circulation in a warming climate. Nature, 451, 286-288, doi:10.1038/nature06590.

Trathan, P. N., M. A. Brandon, E. J. Murphy, and S. E. Thorpe, 2000: Transport and structure within the Antarctic Circumpolar Current to the north of south Georgia. Geophys. Res. Lett., 27, 1727-1730, doi:10.1029/1999GL011131.

Turner, J., 2004: The El Niño-Southern Oscillation and Antarctica. Int. J. Climatol., 24, 1-31, doi:10.1002/joc. 965.

Uddstrom, M. L., and N. A. Oien, 1999: On the use of highresolution satellite data to describe the spatial and temporal variability of sea surface temperature in the New Zealand region. J. Geophys. Res., 104, 20729-20751, doi:10.1029/ 1999JC900167.

Verdy, A., J. Marshall, and A. Czaja, 2006: Sea surface temperature variability along the path of the Antarctic Circumpolar Current. J. Phys. Oceanogr., 36, 1317-1331, doi:10.1175/ JPO2913.1.

Vivier, F., D. Iudicone, F. Busdraghi, and Y.-H. Park, 2010: Dynamics of sea-surface temperature anomalies in the Southern Ocean diagnosed from a 2D mixed-layer model. Climate Dyn., 34, 153-184, doi:10.1007/s00382-009-0724-3. 
Wang, C., L. Zhang, S.-K. Lee, L. Wu, and C. R. Mechoso, 2014: A global perspective on CMIP5 climate model biases. Nat. Climate Change, 4, 201-205, doi:10.1038/nclimate2118.

Wang, Z., T. Kuhlbrodt, and M. P. Meredith, 2011: On the response of the Antarctic Circumpolar Current transport to climate change in coupled climate models. J. Geophys. Res., 116, C08011, doi:10.1029/2010JC006757.

Watts, D. R., C. Sun, and S. Rintoul, 2001: A two-dimensional gravest empirical mode determined from hydrographic observations in the Subantarctic Front. J. Phys. Oceanogr., 31, 2186-2209, doi:10.1175/1520-0485(2001)031<2186: ATDGEM $>2.0 . \mathrm{CO} ; 2$.

Wu, L., and Coauthors, 2012: Enhanced warming over the global subtropical western boundary currents. Nat. Climate Change, 2, 161-166, doi:10.1038/nclimate1353.

Yuan, X., 2004: ENSO-related impacts on Antarctic sea ice: A synthesis of phenomenon and mechanisms. Antarct. Sci., 16, 415-425, doi:10.1017/S0954102004002238. 